\title{
6 Urheberrecht - kein Fundament für Bildung und Wissenschaft
}

„Das Urheberrecht verfehlt seine Funktion mit Bezug auf das wissenschaftliche Werkschaffen in wachsendem Maße“ - Reto M. Hilty: Das Urheberrecht und der Wissenschaftler. GRUR Int 2006, 179.

Seit etwa 35 Jahren - mit der Öffnung des Internets für kommerzielle Geschäfte (vgl. 6.1) - kann eine fortschreitende Kommodifizierung des Umgangs mit Wissen und Information ausgemacht werden. Dieser hat das Urheberrecht Rechnung getragen. Tendenziell ist das Urheberrecht dadurch zu einem Handelsrecht geworden. Unabhängig von dieser Kommodifizierung, aber diese Tendenz verstärkend, ist das Urheberrecht weiter reichlich versehen mit "Musts", die entsprechend gar nicht mehr hinterfragt werden. Salopp könnte man sie als die heiligen Kühe des Urheberrechts bezeichnen - etwas weniger salopp als Tabus oder als dysfunktional gewordene Relikte. Die meisten von ihnen stammen aus der letzten umfassenden Reform des Urheberrechts von 1965, einige gehen bis ins 19. Jahrhundert zurück. Sie sind einschließlich der Reformen von 2017/18 weitgehend unangetastet geblieben.

2015, sozusagen zum 50. Jubiläum des 1965er-Urheberrechts, wurde in einem Sammelband (Dreier/Hilty 2015) problematisiert, ob das deutsche Urheberrecht sich immer noch an dieser 1965 gänzlich neu gefassten Version orientieren soll/kann. In diesem Sammelband werden durchaus von einigen Autoren Fragen gestellt, die auch Gegenstand dieses Textes sind, z. B. ${ }^{136}$

ob der 1965 eingeschlagene Weg des Monismus, also der rechtssystematischen Verbindung von urheberpersönlichkeitsrechtlichen Befugnissen und wirtschaftlichen Verwertungsrechten auch in Zukunft noch gangbar ist“ (mit Verweis der Herausgeber auf den Artikel von McGuire in dem zitierten Band). Auch gerät ,der idealistische Schöpferbegriff in den Blick, der im Lichte künftiger Anforderungen philosophisch überladen erscheinen und durch ein neues Leitbild im Sinne eines Urheberrechts ohne Schöpferprinzip zu ersetzen sein könnte“ (mit Verweis der Herausgeber auf den Artikel von (Peifer 2015) in dem zitierten Band).

Ganz grundsätzlich problematisieren die beiden Herausgeber die Tragfähigkeit des gegenwärtigen Urheberrechtskonzepts: „Sollte sich erweisen, dass die traditionelle Bauweise [des UrhG von 1965 - RK] nicht mehr für ein neues Haus taugt, das den aktuellen Herausforderungen den notwendigen Raum verschafft, sind neue Ideen gefordert, möglicherweise über das Gelände hinaus, auf dem das urheberrechtliche Haus heute steht.“

136 Die folgenden Zitate aus dem Vorwort zu (Dreier/Hilty 2015) S. IX. 
Stellen wir kurz zusammen, was aus der Systematik, was aus den Fundamenten des Urheberrechts für Bildung und Wissenschaft unpassend oder behindernd geworden ist:

(1) Der Niederschlag der Kommodifizierung von Wissen und Information im Urheberrecht (vgl. 6.1)

(2) Die Fiktion des individuellen Schöpfers (vgl. 6.2)

(3) Die Verfestigung der Vorstellung von „Werk“ als Immaterialgut (vgl. 6.3)

(4) Die Fiktion des Immaterialguts (vgl. 6.4)

(5) Der monistische Charakter des Urheberrechts mit seiner Einheit von persönlichkeits- und vermögensrechtlichen Befugnissen (vgl. 6.5)

(6) Die Möglichkeit der Übertragung der den Urhebern exklusiv zustehenden Verwertungsrechte als ebenfalls exklusive Nutzungsrechte der kommerziellen Verwerter (vgl. 6.6)

(7) Die generelle Unbrauchbarkeit von Schranken für Bildung und Wissenschaft (vgl. 6.7)

(8) Das Beharren auf einem einheitlichen Urheberrecht - die in der politischen Regulierung ausgebliebene Berücksichtigung eines auf die besonderen Bedürfnisse ausgerichteten Wissenschaftsurheberrechts (vgl. 6.8)

(9) Die fatale Wirkung des Drei-Stufen-Tests (der negativen Schranken-Schranke) mit der starken Orientierung an den kommerziellen Interessen der Verwerter (vgl. 6.9)

(10) Der Anspruch des Urhebers (zuweilen sogar der Verwerter) auf das Werk als exklusives persönliches intellektuelles Eigentum (Kap. 7)

(11) Der als unaufgebbar eingeschätzte Vergütungsanspruch auch und vor allem bei schrankenbedingten Nutzungen (Kap. 8)

Besonders gravierend und folgenreich sind die beiden letzten Punkte in der obigen Liste. Darauf wird ausführlich in (Kap. 7) und (Kap. 8) eingegangen. In den Kapiteln von Teil II wird auch darauf eingegangen, dass die positive Publikationsfreiheit eines Wissenschaftlers keineswegs uneinschränkbarer Teil seiner Wissenschaftsfreiheit ist. Auch die Ablehnung einer Mandatierung des Zweitverwertungsrechts bzw. die Ausklammerung eines institutionellen Zweitverwertungsrechts gehört zu den nicht mehr zeitgemäßen Relikten (vgl. 11.3.6). 


\subsection{Zur fortschreitenden Kommodifizierung und Ökonomisierung des Urheberrechts}

Das Urheberrecht hat sich vor etwa 50 Jahren zunächst über verschiedene Konferenzen des „Berner Übereinkommen zum Schutz von Werken der Literatur und Kunst“ (nach verschiedenen Überarbeitungen „RBÜ“ genannt) neu bestimmt. ${ }^{137}$ Die Regelungen der RBÜ sind für die Staaten, die es unterzeichnet haben, völkerrechtlich verbindlich. Nach der Stockholmer Konferenz von 1967 wird die RBÜ von der WIPO (World Intellectual Property Organisation), eine UN-Unterorganisation, verwaltet. Seitdem wird das internationale Urheberrecht nicht mehr von der RBÜ als Gesamttext fortgeschrieben, sondern über einzelne ebenfalls völkerrechtlich verbindliche Verträge wie z. B. TRIPS, Teil der WTO, und der WIPO (s. unten). Dennoch bleibt die RBÜ in seiner Systematik und seiner letzten Fassung für alle weiteren Regulierungen des Urheberrechts weltweit verbindlich.

Mit der RBÜ und auch noch mit der 1965er Urheberrechts-Reform in Deutschland konnten Bildung und Wissenschaft ganz gut leben bzw. wurde das Urheberrecht von den Akteuren in Bildung und Wissenschaft nicht als besonders wichtig oder gar als behindernd empfunden. Woran liegt es dann, dass Urheberrechtsregulierungen erst seit gut dreißig (vorbereitet schon seit ca. fünfzig) Jahren vor allem für Bildung und Wissenschaft zu einem Problem geworden sind? Die Antwort ist einfach und in den Folgen gleichermaßen kompliziert: Verantwortlich dafür ist in erster Linie die Kommodifizierung und Ökonomisierung von Wissen und Information - also das, was James Boyle die ,second enclosure movement“ genannt hat. Boyle übertrug damit die negativen Folgen der (ersten) Einzäunung des freien Weidelands im 16. und 17. Jahrhundert in England durch dessen Privatisierung auf die zweite Einzäunung, die Privatisierung von Wissen ab den 60er Jahren des 20. Jahrhunderts zum Zweck der kommerziellen Gewinnerwartung der dieses Wissen verwertenden „Eigentümer“:

\footnotetext{
We are in the middle of a second enclosure movement. It sounds grandiloquent to call it "the enclosure of the intangible commons of the mind," but in a very real sense that is just what it is. True, the new state-created property rights may be "intellectual" rather than "real," but once again things that were formerly thought of as either common property or uncommodifiable are being covered with new, or newly extended, property rights. (Boyle $2003,37)^{138}$
}

137 Ausführlich beschrieben in (Kuhlen 2008) Erfolgreiches Scheitern, Kap. 3.2 Internationale Entwicklung - Intensivierung der Verwertungsrechte, S. 95-119; vgl. auch (Kreutzer 1999) Die Entwicklung des Urheberrechts in Bezug auf Multimedia der Jahre 1994-1998.

138 In (Boyle 2008) wird ausgeführt, wie die „commons of the mind“ entzäunt und in the „public domain“ zurückgeführt werden können. 
Die Weichen für die Kommodifizierung und nachfolgende Ökonomisierung des Umgangs mit Wissen und Information wurden auf der Stockholmer Konferenz 1967 gestellt. Diese Konferenz war deshalb folgenreich, weil schon im Vorfeld zum ersten Mal über eine (negative) Schranken-Schranke debattiert wurde, also um eine Bestimmung, welche den urheberrechtlichen Schrankenregelungen grundsätzliche Grenzen setzen sollte und bis heute setzt. Anlass war die Diskussion um ein neues umfassendes Vervielfältigungsrecht, das dann tatsächlich auf der 1967er Stockholmer Konferenz beschlossen und 1971 in die RBÜ aufgenommen wurde. Mit diesem Recht sollten auch die Schrankenregelungen generell angepasst werden. „Angepasst“ bedeutet seitdem, Schranken (also Nutzungserlaubnisse) vom Gesetzgeber bzw. den Gerichten so eng wie möglich anzulegen bzw. auszulegen. Die Diskussion endete dann mit der Bestimmung des Drei-Stufen-Tests, ${ }^{139}$ der zunächst nur auf das Vervielfältigungsrecht angewendet wurde. ${ }^{140}$ Auf Betreiben Deutschlands wurde übrigens die jetzt geltende Reihenfolge der Stufen festgelegt. Die Berücksichtigung der Verwerterinteressen rückte dadurch in die zweite Stufe, die der Urheber in die dritte Stufe (ausführlicher zum Drei-Stufen-Test in 6.9). Seitdem sind Schranken nur als Ausnahmen, also nur für spezielle Fälle erlaubt. Sie dürfen nicht der normalen (kommerziellen) Verwertung entgegenstehen, und sie dürfen nicht die Rechte der Urheber unbillig einschränken. Die Dominanz der kommerziellen Interessen ist unverkennbar - zumal alle drei Stufen des Tests erfüllt sein müssen. Was veranlasste die Personen, welche die internationalen Urheberrechtsvereinbarungen (RBÜ, WIPO, TRIPS - s. unten) formulierten, und die Politiker, die das in jeweils nationale Gesetze umsetzten, die Nutzung von öffentlich gemachtem Wissen so stark einzuschränken? Wie so oft, ist es die Entwicklung von neuen Technologien, welche die Recht setzenden Instanzen bis heute veranlassen, die bisherigen Gesetze, oft mit Rücksicht auf die kommerzielle Verwertung, neu zu schreiben. Das war schon bei der Urheberrechtsreform von 1965 zu erkennen. In der Stellungnahme des Rechtsausschusses des Bundestags von 1962 heißt es: ${ }^{141}$

„Seit Erlaß der Gesetze ${ }^{142}$ haben sich eine Reihe bedeutender neuer Verwertungsmöglichkeiten für die Werke der Urheber ergeben, die vom Gesetzgeber nicht oder nur unvollkommen

139 Zur Geschichte des Drei-Stufen-Tests vgl. den entsprechenden Artikel in der Wikipedia https://de.wikipedia.org/wiki/Drei-Stufen-Test_(Urheberrecht).

140 „Der Gesetzgebung der Verbandsländer bleibt vorbehalten, die Vervielfältigung in gewissen Sonderfällen unter der Voraussetzung zu gestatten, dass eine solche Vervielfältigung weder die normale Auswertung des Werkes beeinträchtigt noch die berechtigten Interessen des Urhebers unzumutbar verletzt” (RBÜ Art. 9 Abs. 2).

141 Rechtsausschuss Bundestag: https://bit.ly/2m6gknJ.

142 Gemeint sind:

1. dem Gesetz betreffend das Urheberrecht an Werken der Literatur und der Tonkunst vom 
berücksichtigt sind. Dies gilt besonders für Film, Rundfunk und Fernsehen sowie für die modernen Vervielfältigungsverfahren der Tonbandaufnahme, der Fotokopie und der Mikrokopie. Die Rechtsprechung hat sich zwar bemüht, durch rechtsschöpferische Auslegung und Analogie den durch die neuen technischen Mittel aufgeworfenen Problemen gerecht zu werden. Hierbei sind der Rechtsprechung jedoch Schranken gesetzt. Es ist zudem bedenklich, wenn der geltende Rechtszustand sich immer weiter vom Wortlaut der Gesetze entfernt.“

Grundsätzlich neue Verwertungsformen haben sich damals allerdings nur in geringem Ausmaß durch analoge technische Entwicklungen wie Tonband, Foto etc. ergeben. Zur wirklichen technologisch bedingten Herausforderung für die Politik und damit für die Gestaltung des Urheberrechts wurde erst die tendenziell vollständige Digitalisierung aller mit Wissen und Information zusammenhängenden Prozesse und der dadurch möglich gewordenen neuen Informationsdienstleistungen, die über elektronische Netze verteilt und genutzt werden konnten. Der besondere Mehrwert ergab sich dadurch, dass es in den 80er Jahren gelang, die verschiedenen elektronischen Netze kompatibel zu machen und in dem, was heute das Internet heißt, zusammenzufassen. Das wurde bis Mitte der 90er Jahre alleine von der Wissenschaft genutzt (und vom Militär). Die Potenziale des Internets waren aber auch für die Wirtschaft klar erkennbar und die Öffnung des Internets unvermeidbar. Diese Öffnung geschah, wie zu Beginn erwähnt, Ende 1994 mit der Freigabe des Internets für die kommerzielle Nutzung durch die National Science Foundation (NSF). Seitdem gibt es mit Blick auf Wissen und Information die beiden Parallelwelten im Internet, zwei Wissens- und Informationsmärkte die der wissenschaftlichen Kommunikation und die der kommerziellen Verwertung. ${ }^{143}$ Seitdem gibt es nicht nur, aber vor allem in Bildung und Wissenschaft, den Konflikt zwischen der Leitidee des unbeschränkten freien Zugangs zu Wissen und Information und deren freien Nutzung und dem Anspruch der kommerziellen Informationswirtschaft, mit den aus Wissen entstandenen Wissensobjekten über Informationsobjekte nach Prinzipien des Marktes Handel treiben zu dürfen.

Handel über Verlage hat es allerdings spätestens seit der Entwicklung der Drucktechnik mit bewegten Lettern immer schon gegeben. Aber zu einer wirklichen Industrie ist die Informationswirtschaft insgesamt und dann speziell die

19. Juni 1901 - LUG - (RGBl., S. 227) in der Fassung der Gesetze vom 22. Mai 1910 (RGBl., S. 793) und vom 13. Dezember 1934 (RGBl., II S. 1395),

2. dem Gesetz betreffend das Urheberrecht an Werken der bildenden Künste und der Photographie vom 9. Januar 1907 - KUG - (RGBl., S. 7) in der Fassung der Gesetze vom 22. Mai 1910, vom 13. Dezember 1934 und vom 12. Mai 1940 (RGBl., 1 S. 758) und item dem Gesetz über das Verlagsrecht vom 19. Juni 1901 - VerlG - (RGBl., S. 217) in der Fassung des Gesetzes vom 22. Mai 1910.

143 (Kuhlen 1995) Informationsmarkt. 
auf Wissenschaft bezogene Publikationswirtschaft erst durch die fortschreitende Digitalisierung aller Prozesse von Wissen und Information geworden. Die Berechtigung und der volkswirtschaftliche Nutzen der Öffnung des Internets kann somit gar nicht bestritten werden. Für die Informationswirtschaft stellte sich aber sofort das Problem, dass die digitalen Objekte, die verwertet werden sollten, gar nicht so leicht vor unautorisierter Nutzung geschützt werden können - vor allem nur unzureichend durch das damals geltende Urheberrecht. Es ist den Produzenten von digitalen Produkten aber auch sehr schnell klargeworden, dass durch diese Telemediatisierung die klassischen Publikations- bzw. Verwertungsmodelle nicht mehr zu halten sind. Diese Modelle sind abhängig von der Anzahl der verkauften Kopien des einmal erstellten Master-Objekts (des Werks) - sei es ein Film, ein Audiowerk oder eine klassische Text-Publikation. Dieses Modell funktioniert dann nicht mehr ohne Weiteres, wenn die Unterscheidung zwischen Original und Kopie nicht mehr relevant ist. Jede digitale Kopie ist vom Original nicht zu unterscheiden. Die Vervielfältigungskosten und ebenso die Zugriffs- und Nutzungskosten tendieren gegen Null. Ohne regulativen Eingriff reichte die öffentliche Zugänglichmachung des Master-Originals aus, um jedem in der Welt den Zugriff zu ermöglichen. Das, so die herrschende Meinung der Informationswirtschaft, kann kein Geschäftsmodell sein, und das bis Anfang der 90er Jahre geltende Urheberrecht konnte darauf nicht vorbereitet sein. Entsprechend nahmen auch die internationalen und nationalen Regulierungsinstanzen diese Herausforderung an. Seitdem wird so gut wie jede Urheberrechtsreform mit den Nutzungs- aber auch den Missbrauchspotenzialen der digitalen Information und Kommunikation begründet. ${ }^{144}$ Dabei wurde von Seiten der Politik kein Grund gesehen, wegen technischen Entwicklungen die dem Urheberrecht zugrundeliegenden Konzepte (wie Eigentumsschutz) in Frage zu stellen. Hierzu ein Zitat aus der Begründung für InfoSoc 2001:

Die technische Entwicklung hat die Möglichkeiten für das geistige Schaffen, die Produktion und die Verwertung vervielfacht und diversifiziert. Wenn auch kein Bedarf an neuen Konzepten für den Schutz des geistigen Eigentums besteht, so sollten die Bestimmungen im Bereich des Urheberrechts und der verwandten Schutzrechte doch angepasst und ergänzt werden, um den wirtschaftlichen Gegebenheiten, z. B. den neuen Formen der Verwertung, in angemessener Weise Rechnung zu tragen. (EG 5)

Ähnlich wurde auch die Urheberrechtsreform in Deutschland 2003 begründet. Sie wurde systematisch durch die Herausforderung begründet, dass es durch die

144 Ähnlich war die (medien)technische Entwicklung der Anlass für die Entwicklung von Regulierungsmaßnahmen zum Schutz von Privatheit und Datenschutz und -sicherheit und, intensiviert durch die Entwicklung der IKT, in den 80er Jahren des 20. Jahrhundert und heute durch die global operierenden Kommunikationsdienstleistungen der Googles und Facebooks. 


\begin{abstract}
„Entwicklung im Bereich der Informations- und Kommunikationstechnologie, insbesondere der digitalen Technologie" möglich geworden ist, dass "Inhalte jeder Art, damit auch solche, die urheberrechtlich geschützt sind, völlig unproblematisch und ohne Qualitätsverlust über ein weltumspannendes Datennetz in kürzester Zeit verbreitet und übermittelt werden können.“ (vgl. FN 309)
\end{abstract}

Die immer größer werdende Bedeutung der Wissens- und Informationsindustrie für die Gesamtwirtschaft und die Veränderung der Nutzungsformen durch die neuen Technologien hat die politischen Regulierungsinstanzen weltweit veranlasst, diese neuen Märkte auch durch entsprechende gesetzliche regulative Maßnahmen zu schützen und damit zu befördern. Diese Maßnahmen haben wesentlich zu der fortschreitenden Kommodifizierung von Wissen und Information beigetragen. Die Politik weltweit unter der Führung der USA hatte nie die Berechtigung einer Kommodifizierung von Wissen und Information in Frage gestellt. Ganz im Gegenteil. Zeitgleich mit der kommerziellen Öffnung des Internets wurde das internationale System der Regulierungen für geistiges Eigentum neu geordnet. Entscheidend dafür war die im Gefolge der sogenannten Uruguay-Runde (1986-1994) gegründete Welthandelsorganisation (WTO), deren dritte Säule (neben GATT und GATS) TRIPS ist, das Übereinkommen über den Schutz handelsbezogener Aspekte des geistigen Eigentums (Agreement on Trade-Relaxed Aspects of Intellectual Property Rights). ${ }^{145}$ TRIPS wurde mit dem 1.1.1995 gültig. TRIPS sieht, wie es schon im Titel deutlich wird, geistiges Eigentum unter Aspekten des Handels und der weltweiten Wirtschaft. Die WTO kam damit der für den Schutz geistigen Eigentums zuständigen UN-Organisation, WIPO, knapp zuvor. Der entsprechende WTC-Vertrag der WIPO wurde Ende Dezember 1996 von der WIPO in Genf unterzeichnet. In beiden Regelungen (TRIPS und WTC) wurde der Drei-Stufen-Test als verbindlich für Schrankenregelungen aufgenommen (ausführlicher zum Drei-Stufen-Test in 6.9). Entsprechend hat sich die für das Urheberrecht zuständige Politik im Gefolge von TRIPS bzw. den Vorgaben der WIPO davon überzeugen lassen, dass starke Schutzinstrumente gegen das, was damals Piraterie genannt wurde, entwickelt werden müssen. Das wurde realisiert über die verbindliche Anwendung der Regelungen durch den Drei-Stufen-Test in neuen Urheberrechtsregulierungen (z. B. explizit in der InfoSoc-Richtlinie 2001 oder als selbstverständlich angenommen in den deutschen Urheberrechtsreformen seit 2003). Dazu kamen strikte Urheberrechts-Durchsetzungsgesetze ${ }^{146}$ und die

145 TRIPS - https://bit.ly/2k4jhV1.

146 Gesetz zur Verbesserung der Durchsetzung von Rechten des geistigen Eigentums („Durchsetzungsgesetz“), in Kraft getreten am 1.9.2008; Gesetz zur verbesserten Durchsetzung des Anspruchs der Urheber und ausübenden Künstler auf angemessene Vergütung und zur Regelung von Fragen der Verlegerbeteiligung von 2016 (BGBl. I S. 3037). 
Aufnahme technischer Schutzmaßnahmen (DRM) in den 95-er Paragraphen des deutschen Urheberrechts.

Vor TRIPS und WIPO/WTC hatten die Akteure in Bildung und Wissenschaft, wie oben erwähnt, wenig Probleme mit dem Urheberrecht bzw. es war ihnen gar nicht bewusst, dass das Urheberrecht etwas mit ihrer Arbeit zu tun haben könnte. Das änderte sich durch die Regulierungen im Gefolge von TRIPS und WIPO/WTC, z. B. in den USA durch das DMCA (Digital Millennium Copyright Act) 1998, in der EU durch die EU-Copyright-Richtlinie, InfoSoc 2001, und die neue EU Urheberrechts-Richtlinie 2019 und in Deutschland die Urheberrechtsanpassungen 2003-2018 (vgl. Kap. 10-13). Die immer schon starke kommerzielle Dominanz im angelsächsischen Copyright gilt mehr und mehr auch für den europäischen Bereich. Auch in der EU ist klar zu erkennen, dass die vielfachen Urheberrechtsrichtlinien und die entsprechenden Durchsetzungsrichtlinien ${ }^{147}$ überwiegend der Förderung des Binnenmarktes dienen sollten. Die in ihnen formulierten politischen urheberrechtlichen Leitlinien wurde auch weitgehend auf die Werke aus den Bereichen Bildung und Wissenschaft übertragen. Falls Schrankenregelungen zugunsten dieser Bereiche vorzusehen seien, dürften diese die kommerziellen Interessen keineswegs stark beeinträchtigen, entsprechend der zweiten Stufe des Drei-Stufen-Tests. So heißt es in EG 44 der InfoSoc-Richtlinie von 2001:

Die von den Mitgliedstaaten festgelegten Ausnahmen oder Beschränkungen sollten insbesondere die gesteigerte wirtschaftliche Bedeutung, die solche Ausnahmen oder Beschränkungen im neuen elektronischen Umfeld erlangen können, angemessen berücksichtigen. Daher ist der Umfang bestimmter Ausnahmen oder Beschränkungen bei bestimmten neuen Formen der Nutzung urheberrechtlich geschützter Werke und sonstiger Schutzgegenstände möglicherweise noch enger zu begrenzen.

Die EU-Richtlinie von 2001, in ihrer Konzeption entstanden aus den Diskussionen Ende des letzten Jahrhunderts des letzten Jahrtausends, ist eindeutig das Produkt einer Koalition von Staat und Informationswirtschaft. Dadurch, so die hier vertretene Interpretation der Entwicklung,

haben sich weltweit und durch die Umsetzung der EU-Richtlinie [InfoSoc 2001] auch in Deutschland die Regulierungsformen für Produkte geistigen Eigentums eindeutig dahingehend verschoben, dass in der Wertehierarchie die Verwertung von Wissen und Information und dessen Sicherung einen höheren Stellenwert bekommen haben als die freizügige Nutzung im Interesse der Öffentlichkeit und zum Nutzen der einzelnen Menschen. ${ }^{148}$

147 Z. B. Richtlinie 2004/48/EG des Europäischen Parlaments und des Rates vom 29. April 2004 zur Durchsetzung der Rechte des geistigen Eigentums - https://bit.ly/2YK34a7.

148 (Kuhlen 2004b) Wem gehört die Information im 21. Jahrhundert, S. 3. 
In der deutschen Politik hat MdB Günter Krings ${ }^{149}$ diese ökonomische Wende des Urheberrechts auf den Punkt gebracht: 2006 bei der Ersten ${ }^{150}$ und 2007 bei der Zweiten und Dritten Lesung der Urheberrechtsreform des Zweiten Korbs ${ }^{151}$ deutete er das von der Bundesregierung anvisierte Ziel eines bildungs- und wissenschaftsfreundlichen Urheberrechts keineswegs nur ironisch um:

\begin{abstract}
„Als Rechtspolitiker der großen Koalition freuen wir uns über das Bekenntnis im Koalitionsvertrag für ein starkes und wissenschaftsfreundliches Urheberrecht. Wissenschaftsfreundlich passen Sie genau auf - heißt dabei ganz unmissverständlich auch wissenschaftsverlagsfreundlich.“(2006)

Und 2007: „Deshalb [weil die meisten Wissenschaftler nicht nur auf der eigenen Homepage publizieren möchten, sondern auch bei einem Verlag] kann wissenschaftsfreundliches Urheberrecht gar nichts anderes heißen als auch wissenschaftsverlagsfreundliches Urheberrecht.“
\end{abstract}

Fazit. Die starke Ausrichtung des Urheberrechts auf wirtschaftliche Aspekte und kommerzielle Verwertung ist dem Urheberrecht aber nicht zwangsläufig immanent ganz im Gegenteil: das öffentliche Interesse ist die Rechtfertigung für das Urheberrecht als Schutzrecht. Aber die starke politische Unterstützung der kommerziellen Verwertungsinteressen hat dazu geführt, dass die Bezeichnung „Urheberrecht“ mehr zu einer Etikette geworden ist. Nicht nur Reto M. Hilty findet es

absurd [...] dass in der ganzen politischen Diskussion immer und allein vom „Urheber“ die Rede ist. Gemeint sei damit aber keineswegs der Kreative, sondern in aller Regel eben die Urheberrechtsindustrie. ${ }^{152}$

Das Urheberrecht, besonders das Wissenschaftsurheberrecht, ist seit diesen gut 30 Jahren eher zu einem verhindernden (disabling) als zu einem befördernden (enabling) Instrument für den Umgang mit Wissen und Information geworden. Auf der Strecke geblieben ist der umfassende freie Zugang zu Wissen bzw. zu den entsprechenden Wissens- und Informationsprodukten und ihrer freien Nut-

149 MdB Günter Krings, lange Jahre der Berichterstatter der CDU für das Urheberrecht, von 2009 bis Ende 2013 stellvertretender Vorsitzender der CDU/CSU-Bundestagsfraktion und seit Dezember 2013 Parlamentarischer Staatssekretär beim Bundesminister des Innern.

150 Erste Beratung des von der Bundesregierung eingebrachten Entwurfs eines Zweiten Gesetzes zur Regelung des Urheberrechts in der Informationsgesellschaft - Drucksache 16/1828 - https: //bit.ly/2EmZdEq.

151 Deutscher Bundestag - 16. Wahlperiode - 108. Sitzung. Berlin, Donnerstag, den 5. Juli 2007, 11149 - https://bit.ly/2yRNoTj.

152 Interview mit Reto M. Hilty im Dossier Urheberrecht der Bundeszentrale für politische Bildung am 27.11.2007 https://bit.ly/31potD1. 
zung. Die unverkennbare kommerzielle Dominanz im Urheberrecht ${ }^{153}$ hat nicht nur Nachteile für Bildung und Wissenschaft selbst, sondern hat auch negative Auswirkungen auf die Öffentlichkeit, auf jedermann, und insbesondere auch auf die Innovationsfähigkeit der Wirtschaft, also auf die Fähigkeit zur Umsetzung von Wissen in neue Produkte oder in neue Produktionsformen. Die Kommodifizierung von Wissen und Information mit den Folgen der Verknappung der Nutzung ist langfristig nicht im Interesse der Wirtschaft insgesamt. In Kap. 14 wird gezeigt, dass diese umfassende Kommodifizierung seit einigen Jahren für die Informationswirtschaft selbst dysfunktional geworden ist, so dass neue, nutzungsoffene Geschäftsmodelle (unter Anerkennung des Open Access-Paradigmas) gefunden werden (müssen).

In den folgenden Abschnitten wird in Erweiterung der Kommodifizierungsproblematik systematisch auf Probleme eingegangen, die dem Urheberrecht immanent sind und die dafür verantwortlich sind, dass das Urheberrecht eine für Bildung und Wissenschaft problematische Entwicklung genommen hat.

\subsection{Die Fiktion des individuellen Schöpfers}

Am Ende von Abschnitt 5.3 wurde schon auf die Problematik, Autoren als Schöpfer zu bezeichnen, hingewiesen. Damit soll nicht abgestritten werden, dass der Begriff des individuellen Schöpfers in den verschiedenen Bereichen der Kunst, Literatur und Medien berechtigt sein kann - ob dafür auch die Benennung „Schöpfer“ angebracht ist, sei dahingestellt. Schon die Werke in der Unterhaltungsindustrie auf den allgemeinen Publikumsmärken, (Unterhaltung, Spiele etc.) sind i. d. R. nicht das Resultat individueller Schöpfung, sondern werden durch Beteiligung vieler, fachlich sehr heterogener Akteure erstellt, auch solcher mit eher technischen und Marketing-Kompetenzen. Der individuelle Schöpferbegriff mit seinen Konsequenzen für umfassenden Rechts- und Schutzanspruch ist aber vor allem in der Wissenschaft nicht angebracht. Diese Skepsis gilt nicht nur für Werke aus der Großforschung in verteilten Gruppen vor allen in den MINT- bzw. STM-Fächern, sondern für Wissenschaft allgemein - zu stark ist hier die Abhängigkeit von den Vorleistungen und der Mitwirkung Dritter, als dass die Erstellung eines Wissensobjekts als

153 Exemplarisch dazu die Anmerkung des Bundesrats zum ersten EU-Kommissionsentwurf für eine neue Urheberrechtsrichtlinie: „Aus Sicht des Bundesrates bleiben - wie beispielhaft EG 36 zeigt - die vorgeschlagenen Regelungen noch zu sehr in alten Verwertungs- und Wertschöpfungsmodellen verhaftet und rezipieren bislang nur unzulänglich die Realität digitaler Mediennutzung an Hochschulen, Forschungseinrichtungen und den Einrichtungen des Kulturerbes.“ (Bundesrat $565 / 16$ 16.12.169). 
individuelle Schöpfungsleistung angesehen werden kann. Das schmälert in keiner Weise den Wert und die Anerkennung der wissenschaftlichen Produktionsleistung. Arbeiten ist aber in der Wissenschaft in hohem Maße ein kollaborativer und auf Vorleistungen referenzierender Prozess. ${ }^{154} \mathrm{Gehen}$ wir auf einige Aspekte dieses kollaborativen Prozesses ein.

\subsubsection{Kollaboration durch wissenschaftlichen Diskurs}

Die das wissenschaftliche Arbeiten seit vielen Jahrhunderten prägende Form der Kollaboration beruht darauf, dass kein Wissenschaftler produktiv tätig werden kann, ohne auf dem Stand des publizierten Wissens aufzusetzen. Es wird negativ angerechnet, wenn der Stand des erarbeiteten und publizierten Wissens bei einer Publikation nicht berücksichtigt wird. Es würde gegen wissenschaftliches Ethos verstoßen, wenn man sich für den Stand des Wissens alleine auf sich selbst verlässt. Ebenso kann keine Lehrveranstaltung geplant und mit Erfolg durchgeführt werden, wenn nicht eben dieser Stand berücksichtigt wird. Auszubildende haben einen Anspruch darauf, dass ihre Lehrenden sich auf dem Stand des Wissens bewegen und in der Lage sind, dieses Wissen so aufzubereiten, dass es lernbar wird. Jeder Wissenschaftler (Forscher und Lehrende) ist ständig im Diskurs mit anderen Wissenschaftlern, traditionell über deren Werke, in der Gegenwart aber auch immer mehr durch direkten Kontakt - über den Austausch auf Konferenzen oder über elektronische Kommunikationsformen. Waren die Kollaborateure des aktuell an einem Problem arbeitenden und eine Veröffentlichung vorbereitenden Wissenschaftlers die „Giganten“ der Vergangenheit, so sind es heute in den vernetzten Räumen des Internets immer mehr die virtuellen und realen Partner, die mit ihren Anregungen, informellen Beiträgen und in Publikationen veröffentlichten Arbeiten Entscheidendes zum Entstehen neuer Wissensobjekte beitragen. Das Kommunikationsverhalten in der Wissenschaft hat sich mit dem Internet umfassend verändert. ${ }^{155}$

\subsubsection{Kollaboration durch Mehrfachautoren}

Publizieren wird immer intensiver zu einem kollaborativen Vorgang. Seit der zweiten Hälfte des 20. Jahrhunderts nehmen Mehrfachautorenwerke stark zu. Noch um

154 (Kuhlen 2004a) Kollaboratives Schreiben; (Kuhlen 2008) Erfolgreiches Scheitern. Kap. 4.5.4 Kollaboration und Soziale Dienste im Web-2.0-Paradigma.

155 (Cronin 2001): Hyperauthorship: A postmodern perversion or evidence of a structural shift in scholarly communication practices? 
1900 waren (am Beispiel der Chemie) noch ca. $80 \%$ der Werke von Einzelautoren verfasst. Hundert Jahre später ist das Verhältnis (ebenfalls beim Beispiel der Chemie) ein ganz anderes. Bei ca. $90 \%$ der Arbeiten sind Mehrfachautoren angegeben. Arbeiten mit 100 Autoren und mehr sind zwar Ausnahmen, aber kommen vor. ${ }^{156}$ Vor allem in den technischen, medizinischen und naturwissenschaftlichen Fächern werden die Werke überwiegend von Mehrfachautoren verfasst. Taubert (FN 156) weist darauf hin, dass große Autorengruppen von mehr als 10 Autoren seit etwa 2003 besonders stark an Bedeutung gewonnen haben. Taubert geht allerdings davon aus, ,dass nach wie vor die kleinen und mittleren Gruppen zwischen 2-10 Personen dominieren, von denen der größte Anteil stammt, wenngleich dieser in den letzten Jahren zurückgeht. “ Eine bei (STM 2018, 36) referenzierte Analyse von (Economist 2016) weist im Scopus-Material nach, dass die durchschnittliche Autorenanzahl pro Artikel von 3,2 im Jahr 1995 auf 4,4 in 2015 gestiegen ist. Im Extremfall kommen sogar Artikel mit 1000 „Autoren” vor (sogenanntes „hyperauthorship"). ${ }^{157}$ Einzelautorenpublikationen sind außerhalb von Geistes- und Sozialwissenschaften eine seltene Ausnahme.

Dass Publizieren über Mehrfachautoren, zumindest in den angesprochenen Fächern, zur allgemeinen Norm wird, hat vielfache Gründe, auf die wir hier nur knapp eingehen können. Wissenschaft ist in vielen Fällen, wenn nicht sogar Großforschung, so doch thematisch und organisatorisch komplexe projektorientierte Forschung. Diese kann nur noch selten individuell durchgeführt werden, sondern immer mehr arbeitsteilig in größeren Arbeitsgruppen. Zudem werden oft in diesen Gruppen heterogene Kompetenzen aus verschiedenen Disziplinen gebündelt. Das ist auch dadurch bedingt, dass neue Forschung oft in Randgebieten entsteht, die mehrere Disziplinen mit verschiedenen Fragestellungen und verschiedener Methodik betreffen. Zwar wird es weiter so sein, dass meistens ein renommierter hoch-kompetenter Wissenschaftler für die Formulierung der zentralen Forschungsfrage, für die Einwerbung der Mittel und des Aufbaus der

156 (Taubert 2019) Fremde Galaxien und abstrakte Welten. Open Access in Astronomie und Mathematik, 206f; Taubert hat das Open Access Verhalten in den Fächern Astronomie und Mathematik untersucht. Der Anteil von Werken mit Einzelautoren beträgt nur 16,19\%, mit zwei Autoren 19,82\%, 6-10 Autoren 14,86, > 100 Autoren 2,89 (aus Tabelle 9.1).

Stock (Folie 72 aus PP Projektseminar Infometrie SS 2017) gibt ein Beispiel aus Physics Letters B von 5/2003, wo für einen Artikel von 9 Seiten über 200 „Autoren“ geführt werden - https: //bit.ly/2D54dvF; zu den Mehrfachautoren vgl. auch (Hornbostel 1997) Wissenschaftsindikatoren: Bewertungen in der Wissenschaft.; (Brock 2008) Kap. 5.4.2 Mehrfachautorenschaft.

157 (STM 2018): “In 1981, the highest number of authors on a paper indexed by ISI was 118, while by 2015 a paper in Physical Review Letters listed 5,154 authors. The trend has provoked debate over the nature of authorship, with some calling for the term 'contributor' to be distinguished from 'author' in such cases“. 
Arbeitsgruppe zuständig ist. Er ist quasi Urheber=Veranlasser, und er wird auch oft auch als Co-Autor mitgeführt, gleichsam als „Ehrenautor“, auch wenn er zu der konkreten Arbeit eigentlich so gut wie nichts beigetragen hat. Die praktische Forschungsarbeit, die zu einer Publikation führt, wird von verschiedenen oder allen Personen in der Gruppe geleistet. Sie haben entsprechend einem Anspruch auf Sichtbarkeit als Co-Autor. Verstärkt wird diese Tendenz zum kollaborativen Arbeiten und Publizieren in Gruppen dadurch, dass Wissenschaft zunehmend global organisiert ist. Wer ein Kollege oder potenzieller Mitautor ist, entscheidet sich nicht mehr alleine über die lokale institutionelle Nähe, sondern durch das Wissen, wer an vergleichbaren Themen arbeitet. Kontaktaufnahme, laufende Kommunikation, Austausch von Forschungsergebnissen und schließlich kollaborative Werkerstellung werden über elektronische Netze, Dienstleister wie ResearchGate und Academia und elektronische/kommunikative Werkzeuge realisiert.

\subsubsection{Zitierungswahrscheinlichkeit durch Kollaboration}

Sowohl die intensive lokale institutionelle als auch die global organisierte Kollaboration führt also zwangsläufig zu dem Mehrfachautorenphänomen. Mehrfachautorenschaft hat zudem auch einige weitere Vorteile. Die Daten legen es nahe, dass Artikel mit mehreren Autoren eine höhere Wahrscheinlichkeit haben zitiert zu werden als Einzelautorarbeiten. Gerade für jüngere Wissenschaftler vergrößert sich die Chance, dass ihre Arbeiten wahrgenommen werden, wenn ein etablierter Wissenschaftler als Ko-Autor erscheint. Diese Sichtbarkeit wird dann auch auf nachfolgende Publikationen transportiert. Koautorschaft fördert die Einbindung in wissenschaftliche soziale Netzwerke und eröffnet Chancen auf weitere, auch global organisierte Zusammenarbeit. Die Zitierungswahrscheinlichkeit erhöht sich besonders dann, wenn die „Kollaborateure“ sich aus verschiedenen Ländern oder Regionen der Welt rekrutieren: ,articles with 5 additional countries receive nearly three times as many citations as those with none“..158

Bei den Vielfachautorenwerken ist für die Rezipienten dieser Werke allerdings kaum auszumachen, wem von den vielen erwähnten Verfassern/Verantwortlichen das Attribut Autor/Urheber am meisten zukommt - vor allem dann nicht, wenn die Namen der Beitragenden alphabetisch angeordnet sind. Wird die alphabetische Reihenfolge nicht eingehalten, so kann mit einiger Wahrscheinlichkeit davon ausgegangen werden, dass die zuerst Genannten den größten Anteil am Entstehen des

158 Royal Society 2011 - zit. nach STM 2018, 37. 
Werks gehabt haben. Aber dies ist bei den Mehrfachautorenartikeln die Ausnahme. Entsprechenden Studien ist zu entnehmen, dass bei ca. $80 \%$ der Artikel mit drei und mehr Autoren diese alphabetisch angeordnet sind. Wie kann dann Leistung individuell zugerechnet werden? Brock $2008^{159}$ führt drei Strategien an, wie das bestimmt werden könnte:

1) normal counts rechnen jedem Mitautor eine volle Publikation an, was in den meisten von Lindsey durchgesehenen empirischen Studien der Fall ist.

2) straight counts erfassen lediglich den Erstautor. Eine technisch sehr einfache Methode, die auf Cole/Cole (1973) zurückgeht ${ }^{160}$ und davon ausgeht, daß der Erstautor den überwiegenden Teil der Arbeit geleistet hat. 3) adjusted counts rechnen jedem Autor einen Bruchteil des Artikels zu. (a.a. O. S. 347)

Praktische Bedeutung hat dies wohl nicht. Daher merkt auch Brock an: „Da es keine verbindliche Konvention dafür gibt, welche Art von Leistung eine Mitautorschaft begründet, wird zunehmend unklarer, was Autorschaft überhaupt heißt.“ (ebda.). Wird Autorschaft sehr weit interpretiert, dann erscheint jeder als Autor, der irgendwie zum Entstehen der Publikation beigetragen hat. Soll dann jeder „Autor“, auch wenn er zum „geistigen Gehalt“ so gut wie nichts beigetragen hat, den Urheberrechtsschutz als Schöpfer reklamieren können?

\subsubsection{Kollaborative Texte im Hypertextparadigma}

Aus der Hypertextmethodologie stammt der Gedanke, dass es nicht nur die Autoren sind, die sich kollaborativ verhalten, sondern auch die Texte selbst. ${ }^{161}$ George P. Landow widmet in seinem Hypertextbuch ${ }^{162}$ einen eigenen Abschnitt dem kollaborativen Schreiben und der kollaborativen Autorschaft:

Once enscondes within a network of electronic links, a document no longer exists by itself [...] any document placed on any networked system that supports electronically linked materials potentially exists in collaboration with any and all other documents on that system; second, any document electronically linked to any other document collaborates with it. (a. a. 0. 89)

159 (Brock 2008) Globalisierung: Wirtschaft - Politik - Kultur - Gesellschaft, Kap. 5.4.2 Mehrfachautorenschaft, S. $246 \mathrm{ff}$.

160 (Cole/Cole 1973) Social stratification in science. Oxford Academics.

161 In anderer Terminologie hat dieser Gedanke auch die hermeneutische Tradition der Rezeptionsästhetik bestimmt. Auch hier steht nicht mehr der Autor mit seinem Werk in Zentrum der Auslegung.

162 (Landow 1992) Hypertext. The convergence of contemporary critical theory and technology. 
Also sind es nicht nur die Autoren, die sich kollaborativ verhalten, sondern auch die „Texte“, die multimedialen Objekte, und zwar nicht nur durch die in jedem Text durchscheinenden Bezüge auf vergangene Texte, sondern auch und vor allem durch die reale synchrone Vernetzung mit anderen „Texten“, die in der beliebigen Offenheit erst das Prinzip von Hypertext Realität werden lässt. ${ }^{163}$ Durch das World Wide Web, das als Netz vieler Netze selbst als universaler Hypertext angesehen werden kann, wird jeder Text durch das Navigieren im Netzwerk mit anderen Texten oder Textfragmenten verbunden. Ein jeder Text wie auch jedes andere mediale Objekt, einmal ins Netz eingebunden, existiert nicht länger durch sich selbst alleine. Es existiert als Teil eines durchaus instabilen, von der jeweiligen Handlung des Navigierenden abhängigen Texts. Zur gleichen Kategorie gehört das, was heute unter dem Konzept des user-generated content beschrieben wird (vgl. Bauer 2010; Gelke 2013). Dadurch wird auch der dem Urheberrecht zugrundeliegende Werkbegriff (vgl. Abschnitt 5.2) problematisch. Wer ist dann noch der „Schöpfer“ von diesen aktuellen, durchaus flüchtigen, auch durch die Handlung des Navigierenden entstandenen Texten? Wer soll an diesen Texten Urheber- oder Verwertungsrechte haben?

\subsubsection{Schwer nachvollziehbare „Prägetheorie“}

Mit diesen Anmerkungen in den vorangegangenen vier Unterabschnitten zur Kollaboration soll keineswegs in Abrede gestellt werden, dass, trotz deutlichen Tendenzen zur Mehrfach- oder Vielfachautorenschaft und trotz des starken Anteils an kollaborativer, aber auch delegierter Arbeit an Maschinen und Algorithmen, einzelne Personen nach wie vor die Entwicklung des wissenschaftlichen Geschehens prägen. Aber weiter den individuellen, aus dem 19. Jahrhundert stammenden romantisierenden Schöpferbegriff zur Grundlage auch des gegenwärtigen Urheberrechts $\mathrm{zu}$ machen, ist schwierig zu akzeptieren. Was für Goethes Gedichte gelten mag, wirkt heute für wissenschaftliche Werke aus der Zeit gefallen. Vor allem die das Urheberrecht mit der „Prägetheorie“164 leitende Annahme, dass das Werk unauflösbar mit der Persönlichkeit des Urhebers verbunden ist, wird bei zunehmend kollaborativ entstandenen Werken fragwürdig. Wie spiegeln sich die vielfachen Persönlichkeitsrechte in solchen Werken wider (vgl. Mehrautoren-Beispiele in FN 156)? Das jetzige Urheberrecht kann kaum adäquat auf das Mehrfachautoren-

163 Vgl. (Kuhlen 2004a) Kollaboratives Schreiben.

164 Zur Kritik an der Prägetheorie, die Widerspiegelung der künstlerischen Persönlichkeit im Werk, vgl. (Metzger 2002), Rechtsgeschäfte über das Droit moral im deutschen und französischen Urheberrecht, $72 \mathrm{ff}$. 
problem reagieren. ${ }^{165}$ Was folgt praktisch aus $\S 8$ Abs. 1: „(1) Haben mehrere ein Werk gemeinsam geschaffen, ohne daß sich ihre Anteile gesondert verwerten lassen, so sind sie Miturheber des Werkes“? Erst recht kommt das Urheberrecht mit der Kollaborationsrealität in der Wissenschaft nicht zurecht. Das in einem Werk repräsentierte Resultat kollaborativen Arbeitens ist mehr als nur die Summe der einzelnen „Autoren“ in einer Mehrfachautoren-Publikation. (Hugenholtz et al. 2006) sehen urheberrechtlichen Klärungsbedarf bei anonymen, kollaborativen, kollektiven und gemeinsamen Werken:

The boundaries between various concepts are rather fluid, particularly where collaborative works are concerned. Some legislations seem to grant the co-author a separate copyright in his or her contribution, while the term of protection is dependent on the last surviving of all the coauthors. Others regard collaborative works as one, i.e. without separate copyrights for the individual co-contributors (although they generally are free to exploit their own contribution separately as long as it does not harm the work as a whole). In some Member States the concept of a joint work (inseparable whole) is incorporated in the concept of collaborative work, which may be a work with or without identifiable contributions. ${ }^{166}$

Tatsächlich deckt der Urheberbegriff mit der Emphase auf den individuellen Schöpferbegriff kaum noch die Realität des Schutzbereichs des Urheberrechts ab. Auch Peifer $2015^{167}$ stellt im Titel seines Artikels die programmatische, aber doch eher rhetorisch formulierte Frage „Festhalten am idealistischen Schöpferbegriff?“ Dieser erinnere an den „christlich-abendländischen Schöpfer“. Aber es geht hier nicht nur um eine leicht zu vernachlässigende theologische Assoziation, sondern auch darum, dass der Schöpferbegriff, philosophisch und emotional hoch aufgeladen, Konsequenzen für die Systematik des Urheberrechts hat. Der Schöpferbegriff steht für Peifer

in einem besonders engen Zusammenhang mit idealistischen (oder prinzipiengeleiteten) Begrifflichkeiten einer philosophischen Aufladung des Urheberrechts durch seine Identifikation mit einer naturrechtlichen Vorstellung vom (geistigen Eigentum), das nicht durch ein Gesetz verliehen, sondern allenfalls anerkannt und mit staatlichem Rechtsschutz durchsetzungsfähig gestaltet werden muss. (a. a. 0. 351)

Entsprechend wird in dieser Arbeit der Schöpferbegriff vermieden und dafür die auch nicht unproblematische, aber doch emotionsfreiere Bezeichnung „Autor“ verwendet. Diese Kritik an dem Schöpferbegriff muss nicht automatisch das ins

165 Vgl. (Lerner/Lin 2012) Collaboration in intellectual property.

166 (Hugenholtz et al. 2006) The recasting of copyright \& related rights for the knowledge economy, S. 147.

167 (Peifer 2015) Festhalten am idealistischen Schöpferbegriff? 
Recht setzen, was im US-amerikanischen Copyright möglich ist. Durch dieses mit dem dort zur Anwendung kommenden Prinzip ,work for hire“ kann der Arbeitgeber eines Autors oder auch eine andere Institution wie z. B. ein Verlag als Herausgeber eines Sammelbandes das originäre Copyright für die Verwertung des Werks erhalten, auch wenn dem Ersteller des Werks weiter zugestanden wird, als Autor aufzutreten. Copyright und Autorschaft ("Schöpfer") können also getrennt voneinander sein. Das Copyright erhält derjenige, der sozusagen als "creator”, als Initiator für das Schaffen des Werks zuständig war. Diese Möglichkeit des „work for hire“ entspricht dem im Copyright stärker ausgeprägten Gedanken, dass ein Werk durchaus bzw. in erster Linie als ein Wirtschaftsgut angesehen ist. Der ökonomisch relevante Stimulus und die Bereitstellung des Werks auf dem Markt haben die höhere Priorität. Eine ähnliche Tendenz zur kommerziellen Ausrichtung des Urheberrechts ist, wenn auch nicht in Richtung zum ,work for hire“, auch im deutschen Urheberrecht zu erkennen. ${ }^{168}$

Fazit. Die bislang geltende exklusive Zuordnung des Urheberrechts zu einem persönlichen individuellen Urheber/Schöpfer ist nicht haltbar. Den individuellen, aus dem 19. Jahrhundert stammenden romantisierenden Schöpferbegriff zur Grundlage auch des gegenwärtigen Urheberrechts zu machen, ist nur noch schwer zu akzeptieren. Werke werden in Bildung und Wissenschaft nicht geschaffen, sondern können nur durch den nutzenden Austausch mit den Publikationen anderer Wissenschaftler entstehen. Der heute wie aus der Zeit gefallene Begriff des Schöpfers eines Werks als Ausdruck seiner Persönlichkeit sollte nicht mehr zur Begründung der Rechte an den wissensrepräsentierenden Werken verwendet werden. Der urheberrechtliche Begriff des individuellen Schöpfers/Autors wird durch den des kollaborativen Autors erweitert, wenn nicht sogar ersetzt. Das auf individuelle Leistungen bezogene Urheberkonzept ist dem in hohem Maße kollaborativen und vernetzten Wissensproduktionsprozess nicht angemessen. Tatsächlich kommt das jetzige Urheberrecht mit der Kollaborationsrealität in der Wissenschaft nicht zurecht und berücksichtigt den institutionellen Beitrag an der Produktion eines Werks nicht befriedigend.

168 Vgl. (Wandtke 2017) Urheberrecht, S. 28. 


\subsection{Zur Problematik von Werk/Immaterialgut - Werkstück/Materialgut}

Schon in 5.2 wurde auf die systematisch/dogmatische Unterscheidung zwischen „Werk“ und „Werkstück“ eingegangen, wie sie seit Ende des 18. Jahrhunderts im Urheberrecht entwickelt wurde und bis heute gültig ist. Das Werk ist sozusagen das Substrat der „Schöpfung“ des Urhebers, welches als Immaterialgut und als Ausdruck der Persönlichkeit des Urhebers den Anspruch auf geistiges Eigentum begründet. Hier hängt also alles zusammen: Schöpfer, Werk, Immaterialgut und geistiges Eigentum. Dieser Zusammenhang fehlt beim „Werkstück“. Es wird nicht geschaffen, sondern als anfassbares Produkt (z. B. als Buch) produziert. Es ist nicht immateriell, sondern materiell. Trotzdem werden im Interesse der Verwerter auch die materiellen Werkstücke durch das Urheberrecht geschützt, und die Verwerter reklamieren, ohne Schöpfer zu sein, ebenfalls den Anspruch des Schutzes des geistigen Eigentums. Das ist auch systemimmanent schwer nachvollziehbar.

Aus dem geistigen Eigentum des Urhebers werden nicht nur die Persönlichkeitsrechte, sondern auch die Verwertungsrechte (Vervielfältigen, Öffentlich-Zugänglich-Machen etc.) abgeleitet. Sie dürfen ihr geistiges Produkt, ihr Immaterialgut, verwerten. Allerdings erlaubt das Urheberrecht (\$29) auch die Übertragung der Verwertungsrechte der Urheber als Nutzungsrechte durch die Verwerter. Die Werkstücke dürfen also genutzt werden - das war ja auch die lange Tradition des alten Urheberrechts als Privilegienrecht, das im Interesse der Verleger den unerlaubten Nachdruck von Büchern untersagte bzw. unter Strafe stellte. Heute wird die Verwerternutzung ontologisch/metaphysisch so hoch über den Eigentumsbegriff aufgehängt, dass der Verwerter quasi zum geschützten Urheber wird (vgl. 5.5 und 6.6). Keineswegs wird bestritten, dass die Erstellung, Verbreitung und Bekanntmachung von Werkstücken (Informationsobjekten, wie sie hier genannt werden) eine auch vergütungswürdige Leistung der Verwerter ist. ${ }^{169}$ Dafür müsste aber nicht das Urheberrecht bemüht werden. Zeitgemäß könnte unter besonderen Bedingungen ein Leistungsschutzrecht für Verleger auch von wissenschaftlichen Werken sein so wie es in Deutschland (höchst problematisch) versucht und jüngst auch in der EU-Reform von 2019 zugunsten von Presseverlegern allgemein festgelegt wurde (vgl. 11.4). Bislang haben es die wissenschaftlichen Verleger abgelehnt, ein solches

169 Vgl. den Ansatz von DEAL, bei dem die Öffentlichkeit bzw. die von ihr finanzierten Organisationen dem Anspruch von Verlagen für die Vergütung ihrer Leistungen zur Produktion und Öffentlichmachen von Informationsobjekten Rechnung trägt - allerdings nur für diese Leistungen. Die Nutzung selber soll frei sein (ausführlich zu DEAL 14.8). 
für sich zu reklamieren - mit nachvollziehbarem Grund; denn dann würde der vertraglich gesicherte Transfer des geistigen Werks auf das immaterielle Werkstück von dem primären Schutz des Urheberrechts abgekoppelt. Die Unterstützung des geistigen Eigentumsanspruchs des Urhebers (auf sein geistiges Werk) durch die Verwerter ist aus funktionalen Gründen (Schutz der Verwertung durch das Urheberrecht) durchaus nachvollziehbar.

Fazit. Weder die Begründung des Urheberrechts und des geistigen Eigentums durch die geistige Schöpfung des Werks noch der Schutz der Werkstücke der Verwerter durch einen abgeleiteten Anspruch auf geistiges Eigentum ist für die Situation in Bildung und Wissenschaft plausibel. Das wird in den folgenden Abschnitten zur Fiktion des Immaterialguts (6.4), zum Monismus des Urheberrechts (6.5) und zum Zusammenhang von Verwertungs- und Nutzungsrechten (6.6) ausgeführt. Gesondert wird in Kap. 7 auf Eigentum/geistiges Eigentum und in Kap. 8 auf die Vergütungsproblematik eingegangen.

\subsection{Zur Fiktion des Immaterialguts}

Für das Urheberrecht wird der Schutz des geistigen Eigentums als grundlegend angesehen. Die gegenwärtig stark gewordene Kritik an dieser Begründung bzw. an der Verwendung von „geistigem Eigentum“ vor allem in der Wissenschaft hat vielfach dazu geführt, dass für das Urheberrecht der Begriff des Immaterialgüterrechts verwendet wird. Das verschlimmbessert die Sache aber nur. Der Begriff des Immaterialguts bzw. des Immaterialgüterrechts geht auf das 19. Jahrhundert zurück, i. d. R. mit Referenz auf Josef Kohler. Das ist aber keinesfalls quasi naturrechtlich aus dem Himmel gefallen. Peukert hat in seiner brillanten Kritik der Ontologie des Immaterialgüterrechts ${ }^{170}$ überzeugend nachgewiesen, dass die Veränderungen in den Rahmenbedingungen seit dem späten 18. Jahrhundert zu einer anderen Einstellung gegenüber den Objekten geführt haben, die den Schutz rechtlicher Regulierung genießen:

Vorher war es schlicht und ergreifend undenkbar, den Eigentumsbegriff auf etwas anderes als körperliche Gegenstände anzuwenden: ohne Objekte kein Eigentum. (a.a. O. 72)

Peukert meinte mit den Veränderungen zunächst zum einen die Entwicklung einer bürgerlichen Gesellschaft von autonomen Subjekten, wenn auch erst nur ansatzweise mit politischen Mitwirkungsmöglichkeiten, aber vor allem mit individuellen

170 (Peukert 2018) Kritik der Ontologie des Immaterialgüterrechts. 
Freiräumen für die Entwicklung einer von der Obrigkeit unabhängigen Marktwirtschaft. Zum anderen beschränkte sich das aufklärerische Konzept des autonomen Subjekts nicht nur auf ökonomische, marktwirtschaftliche Aktivitäten, sondern auch auf die schöpferischen Aktivitäten zur Kreation von Erfindungen und neuen Werken. Das begründete die moderne Ausprägung nicht nur von Naturwissenschaft und Technik, sondern auch die von Ästhetik. Nicht länger gilt die klassische Mimesis-Idee, die Nachahmung des von der Natur und von Gott Vorgegebenen, sondern das Schaffen eines Originals, eines neuen unabhängigen Werks durch einen autonomen, romantisch überhöhten Autor/Schöpfer. Der Autor schafft „das“ ideale immaterielle Werk und kann dafür Eigentum, nun eben geistiges Eigentum reklamieren.

Von diesem Werk sind die vielfachen Reproduktionsexemplare zu unterscheiden (vgl. 5.2), die auf Grund der bis heute immer weiter entwickelten Reproduktionstechnologien vor unerlaubten Nachdruck kaum geschützt und für die folgerichtig keine Eigentumsansprüche reklamiert geschweige denn durchgesetzt werden können. Deshalb ist das Schutzobjekt des modernen Urheberrechts nicht das konkrete Reproduktionsobjekt (das Werkstück, wie in der Rechtswissenschaft genannt wird), sondern das immaterielle Werk, das Immaterialgut, wie es seit Ende des 19. Jahrhundert durch Kohler vorgeschlagen wurde. Die Kombination von „immateriell“ und „Gut“ legt nahe, dass es sich bei diesen Immaterialgütern um etwas Reales handelt und damit die Möglichkeit sich eröffnet, das für das Gut als Sachobjekt geltende Eigentumsrecht auf das Gut als Immaterialobjekt zu übertragen. Aber, wie es die Studie von Peukert deutlich macht, handelt es sich dabei um gänzlich unterschiedliche Ontologien für die Objekte des Sacheigentums und für die immateriellen Objekte des geistigen Eigentums. Fraglich sogar, ob das, was als immaterielle oder geistige Objekte bezeichnet wird, überhaupt einen ontologischen Status haben kann - vereinfacht gesprochen: ob das, was so angesprochen ist, tatsächlich selbständig existiert. Oder ob es erst dadurch existiert, dass es über materielle Repräsentationen (wie z. B. Bücher, Bilder, Noten) rezipiert, interpretiert und zu Handlungen in den verschiedenen Lebenswelten führt. Immaterialgut ist, nach Peukert, nur ein artifizielles Konstrukt, eine Fiktion, dem tatsächlich keine ontologische Realität entspricht. Trotzdem kann diese Fiktion - im Sinne von Vaihingers Als-ob - durchaus Relevanz durch rechtliche Realität bekommen.

Die Veränderungen in den Rahmenbedingungen sind aber durchaus breiter zu sehen als nur durch den Bezug auf das sich freisetzende bürgerliche Subjekt im 19. Jahrhundert. Peukert hat für diese Rahmenbedingungen zwar nicht auf die “constraints” von Lessig zurückgegriffen (hier Regulierungsinstanzen genannt; vgl. 4.2), aber ein vergleichbar differenziertes Modell vorgeschlagen, das für ihn erklären konnte, weshalb sich im 19. Jahrhundert die Konzepte des Immaterialguts 
und des geistigen Eigentums verfestigen konnten, welche die Voraussetzungen für die bis heute fortschreitende Kommodifizierung auch von Wissen und Information sind:

Auch im Falle der Vorstellung vom abstrakten Immaterialgut [bedurfte es] eines ganz bestimmten historischen, wirtschaftlich-sozialen Kontexts, damit diese zunächst exzentrische und noch heute erstaunliche institutionelle Tatsache soziale Anerkennung erlangen konnte. (a.a. 0. 47)

Voraussetzung für die Idee des Immateriellen waren für ihn verschiedene „Kontexte“: a) technologischer Fortschritt (z. B. Reproduktionstechniken); b) fundamentaler Wechsel des klassischen Prinzips der Nachahmung zu dem (romantischen) genialer Innovation; c) Wandel der absolutistischen Gesellschaftsordnung zu einer bürgerlichen Marktwirtschaft, bei der alle Arbeitsergebnisse handelbar sind. Weiterführend ist in seinem Modell die unter (c) angesprochene Verbindung von sich verändernder Gesellschaftsordnung und bürgerlicher Marktwirtschaft. Hiermit bringt er in das Lessig'sche Modell der vier Instanzen eine 5. Instanz ein: die politische Ordnung der Gesellschaft.

Die Referenz auf die verschiedenen Kontexte reichte noch nicht für den „Siegeszug“ des Immaterialguts aus. An sich ist dieses Konzept ja nichts weiter als Ideologie in Reinkultur. Aber die Fiktion des Immaterialguts, das so zu tun, als ob es so etwas tatsächlich gibt, ist für Ordnungszwecke nützlich und hat Folgen. Erst dadurch, dass für das Werk ein Gut ins Spiel kommt, entstehen Eigentumsansprüche. Ein Gut, auch wenn es als Immaterialgut ja gar nicht existiert, kann als Objekt deklariert juristischen Regeln unterworfen und als eigentumsfähiges Objekt auf den Märkten gehandelt werden. Mit Gütern kann gehandelt werden. Güter können kommodifiziert werden und können Gegenstand der Ökonomisierung werden. Schließlich können Güter bezüglich der Schutzansprüche, aber auch über Ausnahmen zur Nutzung durch das Recht reguliert werden. Seitdem tun Rechtspraxis und Rechtswissenschaft so, als ob dieses Immaterialgut tatsächlich existiert. Dabei existiert so etwas Entsprechendes nur in der Sprache, durch das Reden darüber. (Peukert 2018, 118ff) weist mit Rückgriff auf die Searle'sche Sozialontologie nach, wie dem an sich „unplausiblen Paradigma“ des Immaterialguts durch entsprechendes Reden darüber der Übergang von sozialer Anerkennung zu sozialer Wirklichkeit gelingt - und zwar durch eine Verankerung des geistigen Eigentums an diesem Immaterialgut im Recht. Dies ist tatsächlich bis in die Gegenwart gelungen.

Fazit. Es ist an der Zeit, die Fiktion des Immaterialguts und damit auch die daraus abgeleiteten Regulierungshandlungen durch das Urheberrecht aufzugeben. Sie hat in ihrer pragmatischen Relevanz einmal eine bedeutende Emanzipationsund Autonomierolle für kreative Autoren gespielt, ist aber heute, wie aus der Zeit 
gefallen, dysfunktional geworden. Die negativen Folgen eines im 19. Jahrhundert akzeptierten sozialen Konstrukts sind heute größer als dessen damalige nützlichen Folgen. Das heutige Reden über die Entstehung von Wissensobjekten und die dem Reden zugrundeliegenden Leitideen haben wenig mit den Fiktionen von Immaterialgüterrecht und Schöpfer zu tun, und erst recht kann dieses Reden nicht mehr als Anerkennung der Wissensobjekte als persönliches geistiges Eigentum verstanden werden. ${ }^{171}$

\subsection{Zum monistischen Ansatz des Urheberrechts}

In den Abschnitten 5.4 und 5.5 sind wir ausführlicher auf die Persönlichkeitsrechte respektive die Verwertungsrechte eingegangen. Hier steht die Besonderheit des deutschen Urheberrechts im Vordergrund, dass die beiden Rechte, die „persönlichkeits- und vermögensrechtlichen Befugnisse“, als „untrennbar miteinander verwoben(e)“ Einheit angesehen werden. ${ }^{172}$ Der Zusammenhang beider Rechtegruppen wird durch $\S 11$ UrhG unter Einhaltung eines einheitlichen Prinzips geklärt. Das Urheberrecht „schützt den Urheber in seinen geistigen und persönlichen Beziehungen zum Werk“ (Satz 1) (also in seinen Persönlichkeitsrechten). Aber „es dient zugleich der Sicherung einer angemessenen Vergütung für die Nutzung des Werkes“ (Satz 2). Dem sollen die Verwertungsrechte (§§ 15 ff.) entsprechen. Diese Einheitlichkeit macht das monistische Prinzip aus. Die ideellen und die materiellen Interessen des Urhebers sind untrennbar miteinander verbunden sind und werden entsprechend im UrhG zusammen geschützt. Es sind vor allem die exklusiven Verwertungsrechte, welche die ökonomischen Rechte des jeweiligen Schöpfers/Autors eines Werks über eine angemessene Vergütung sichern sollen. Aber letztlich leiten sich die Verwertungsrechte aus den unaufgebbaren Persönlichkeitsrechten ab.

171 (Peukert 2018, 166) hat seine Kritik am Ausschließlichkeitsrecht (also das Recht an Eigentum des Immaterialguts) „als radikal, aber nicht als extrem“ bezeichnet. Er hat sich daher zuweilen schwergetan, für das heutige „Reden“ darüber „eine passende Begrifflichkeit zu finden, die einerseits die Fiktion des abstrakten Immaterialguts verabschiedet, zugleich aber an der Form des ausschließlichen Rechts festhält.“ (171) Für einen Juristen mag es schwierig sein, auf im Recht eingeführte Begriffe zu verzichten. So sieht er z. B. keine Alternative für „Werk“ (ebda.). Aus informationswissenschaftlicher Sicht wurde hierfür „Wissensobjekt“ als Alternative eingeführt und „Informationsobjekt“ für das daraus abgeleitete „Werkstück“. Auch lehnt er zwar die Verwendung von „geistigem Eigentum“ ab, aber schlägt die Bezeichnung „IP-Rechte“ vor - vielleicht in der (allerdings vergeblichen) Hoffnung, dass in der Abkürzung „IP“ nicht mehr „intellectual property“ assoziiert wird. Die „schillernde Rede“(ebda.) von geistigem Eigentum bleibt so erhalten. Wir haben als Alternative „Nutzungsrechte“ vorgeschlagen - aber in doch ganz anderer Bedeutung als sie durch das von ihm in Erwägung gezogene alte, erneuerte Privilegienrecht nahegelegt wird (ebda.). 172 Vgl. (Schack 2015) Urheber- und Urhebervertragsrecht, RN 343. 
Die monistische Theorie bringt also zwei gänzlich verschiedene Sichten zusammen. Bis weit ins 19. Jahrhundert stand allerdings die vermögensrechtliche Sicht auf das Urheberrecht im Vordergrund. Erst Mitte des 19. Jahrhunderts wurde die Einschätzung des Urheberrechts als Vermögensrecht durch die Sicht auf das Urheberrecht als individuelles Persönlichkeitsrecht ergänzt. Das trifft insbesondere für die kontinentaleuropäische Urheberrechtstradition zu. Das Werk ist sozusagen aus der Persönlichkeit des Urhebers geschaffen und wird wiederum dadurch Teil seiner Persönlichkeit. Diese Sicht begründete sich aus der quasi naturrechtlichen Einschätzung der Werke von Urhebern als deren geistiges Eigentum. Recht und Schutz der kreativen schöpferischen Persönlichkeit ist das allgemeine Prinzip des Urheberrechts. Die besondere Bedeutung wird auch durch die Systematik des Urheberrechtsgesetzes in Deutschland deutlich. Die Persönlichkeitsrechte werden den Verwertungsrechten vorangestellt. Diese Verbindung der geistigen und persönlichen Beziehung des Schöpfers/Autors zum Werk mit dem Anspruch auf angemessene Vergütung war nicht immer so eindeutig im Urheberrecht kodiert. Im deutschen Urheberrecht von 1965 war vom Schutz kommerzieller Interessen noch nicht explizit die Rede. §11 lautete lediglich: „Das Urheberrecht schützt den Urheber in seinen geistigen und persönlichen Beziehungen zum Werk und in der Nutzung des Werkes (§11). ${ }^{173}$ Erst 2002 wurde das Prinzip der angemessenen Vergütung über den neuen Satz 2 in $\S 11$ direkt festgeschrieben. Satz 2 in Art. 11 (s. oben) wird oft als die einfachgesetzliche (positive) Umsetzung von Art. 14 Abs. 3 des Grundgesetzes verstanden: „(3) Eine Enteignung ist nur zum Wohle der Allgemeinheit zulässig. Sie darf nur durch Gesetz oder auf Grund eines Gesetzes erfolgen, das Art und Ausmaß der Entschädigung regelt.“

Es wird allerdings hier in Frage gestellt, ob zum einen die genehmigungsfreie Nutzung von Werken oder Teilen von ihnen als „Enteignung“ bezeichnet werden kann und ob zum anderen „Entschädigung “ mit monetärer Vergütung gleichgesetzt werden kann. Zudem lässt Satz 2 von §11 einigen Spielraum durch die Verwendung des Prädikats, des unbestimmten Rechtbegriffs ,angemessen“. „Angemessen“ kann - das wird in den Kommentaren, aber auch in der rechtsetzenden Politik nicht bestritten - auch in Richtung Null-Vergütung gehen (vgl. Abschnitt 6.9 und Kap. 8). Anlass für die Einführung von ,angemessene Vergütung“ war die 2002 erfolgte Regelung des Urhebervertragsrechts über die $\S \S 31$ ff UrhG. Dadurch wurde der in der Rechtsprechung allerdings schon früher formulierte Beteiligungsgrundsatz gesetzlich verankert, der sicherstellen soll, dass der Urheber angemessen an den Erträgen aus der Verwertung seiner Werke (in der Regel durch Verleger) zu beteiligen sei. Diese explizit erst spät erfolgte Verankerung eines angemessenen Vergütungsanspruchs ist ein weiterer Hinweis darauf, dass das Urheberrecht sich

173 Urheberrecht 1965 - https://bit.ly/2kxuWMg. 
tendenziell immer stärker der kommerziellen Relevanz von Wissen und Information verpflichtet fühlt - und sei es hier zunächst mit Blick auf die Urheber selbst (aber das gilt dann auch für die Interessen der kommerziellen Verwerter).

Fazit. Die monistische Theorie wird weiter als Grundpfeiler des Urheberrechts angesehen. Für das Wissenschaftsurheberrecht ist diese Einheit mehr als fraglich. In der Wissenschaft besteht ein ganz anderer Begriff für „Verwertung“ als der, der als vermögensrechtliches Interesse Teil des monistischen Anspruchs ist (vgl. 6.8.2 und Kap. 8). „Verwertung“ ist hier „Veröffentlichung“. Dieses ist in der Tat die exklusive Zuständigkeit des/der wissenschaftlichen Autors/en - sei es durch Verbreitung, Vervielfältigend oder öffentliche Zugänglichmachung. Zusammen mit Argumenten, die im Laufe dieses Textes entwickelt werden, kommen wir hier zu dem Ergebnis, dass die monistische Lehre für das Wissenschaftsurheberrecht nicht geeignet ist. Für den Schutz der in Bildung und Wissenschaft Tätigen reichten die Persönlichkeitsrechte aus - mit dem am Ende von Abschnitt 5.4 geäußerten Zweifel, ob dafür die Bezeichnung „Persönlichkeitsrechte“ noch weiter angemessen ist.

\subsection{Die Umwandlung von Verwertungsrechten in Nutzungsrechte}

Wie in 5.5 ausgeführt sieht das Urheberrecht die Möglichkeit vor (geregelt über $\S 29$ ), dass der Urheber per Vertrag oder durch stillschweigende Übereinkunft seine Verwertungsrechte als Nutzungsrechte an Dritte überträgt. I.d.R sind das kommerzielle Verlage. Dieses Zusammenspiel von Verwertungsrechten und Nutzungsrechten ist ein schwierig zu durchschauendes bzw. ein typisches „Im-Prinzip-“ und „Als-ob“-Konstrukt. Der Urheber hat weiterhin die Verwertungsrechte. Sie sind im Prinzip unaufgebbar. Aber faktisch ist das folgenlos. Der Urheber darf seine Rechte vertragsgemäß ohne Sondererlaubnis des Verlags nicht mehr wahrnehmen. Das kann dazu führen, dass ein Autor die ihm zustehenden Verwertungsrechte faktisch nicht mehr ausüben kann, z. B. durch Anzeige seines Werks auf seiner eigenen Website. ${ }^{174}$ Das ist ein starker (allerdings von ihm selbst „,verschuldeter“)

\footnotetext{
174 Hierfür nur ein Beispiel: „So erinnert sich Thomas Dreier, Professor am Institut für Informationsrecht der Universität Karlsruhe, an einen eigenen Artikel, den er im Informatik-Spektrum publiziert hatte. „Als ich den mir neulich einmal herunterladen wollte, musste ich zu meinem Entsetzen feststellen, dass ich mir diesen Artikel für 30 Dollar pro Stück nur einmal herunterladen kann. Und wenn ich mir den Vertrag mit dem Springer-Verlag anschaue, dann habe ich auch nicht das Recht, ihn zum freien Download auf meine Webseite zu stellen.“ - nach (Siegmann 2006) Der Kulturkampf über den Zugang zu wissenschaftlichen Veröffentlichungen verschärft sich.
} 
Eingriff in sein Urheberrecht. Man kann aber inzwischen davon ausgehen, dass viele Verlage die Selbstpublikation auf der Website in ihren Verträgen explizit erlauben oder stillschweigend tolerieren, solange auf das publizierte Werk referenziert wird. Bislang ist keine Klage von Seiten eines Verlags gegen diese Praxis bekannt geworden.

Der Gesetzgeber hat in die bislang weitgehend übliche Vertragspraxis der vollständigen und für die gesamte Schutzdauer des Urheberrechts geltende Rechteübertragung nicht direkt eingegriffen. Er hat also keine Beschränkung der Übertragung auf einfache Nutzungsrechte in $\S 29$ vorgesehen. Im Gegenteil - er hat mit dem Zweiten Korb 2008 sogar die Übertragung für bis dahin noch unbekannte Nutzungsarten ausdrücklich durch Streichung eines bis dahin geltenden Übertragungsverbots ausgeweitet. Allerdings hat er seit $2014 \mathrm{im}$ UrhG über einen neuen Absatz 4 in $\S 38$ ein nicht durch Verträge abdingbares Zweitverwertungsrecht vorgesehen. Dieses greift zwar nicht in die umfassenden Erstverwertungsrechte der Verleger ein, aber gibt den primären Rechtsinhabern doch ein Stück Verfügungsautonomie zurück. Aber dies ist mit so viel Einschränkungen verbunden, dass es unbrauchbar und praktisch wenig genutzt wird (vgl. 11.3). Bei der vertraglichen Rechteübertragung tut der Gesetzgeber so, als ob nun der kommerzielle Verwerter dadurch - zumindest was die Verwertung/Nutzung angeht - im gleichen Umfang Rechtsinhaber des Werks geworden ist wie es dem Urheber zusteht. Dann ist es auch nicht weit von der Als-ob-Einschätzung, dass dem neuen Rechtsinhaber auch die Eigentums- und Vergütungsansprüche des Urhebers zustehen.

Dazu ein kleiner Exkurs zum Begriff des Rechtsinhabers. Im deutschen Urheberrecht ist der Begriff des Rechtsinhabers erst unter dem Einfluss der InfoSoc-Richtlinie von 2001 eingeführt worden. InfoSoc verwendet an vielen Stellen den Begriff "rightsholder", der dann direkt ins Deutsche übertragen wurde. Das Urheberrecht reserviert entsprechend dem Begriff des Rechtsinhabers nicht ausschließlich auf den tatsächlichen Urheber. In $\S 10$ UrhG Abs. 2 ist z. B. geregelt, dass auch ein Herausgeber als Rechtsinhaber anerkannt werden kann, wenn der Urheber eines im Sammelband veröffentlichten Werks nicht bekannt ist oder wenn der Urheber nur unter einem Pseudonym veröffentlicht hat und kein Bezug zu seinem wirklichen Namen hergestellt werden kann. Ist auch der Herausgeber nicht bekannt, wird dadurch der den Sammelband publizierende Verlag zwar nicht Urheber, aber doch uneingeschränkter Rechtsinhaber. Dass das Urheberrecht Verlegern durch den vertraglich abgesicherten Erwerb der Nutzungsrechte den Status des Rechtsinhabers zubilligt, wird u. a. durch $\S 95$ a Schutz technischer Maßnahmen belegt. In Abs. 1 heißt es: „Wirksame technische Maßnahmen zum Schutz eines nach diesem Gesetz geschützten Werkes oder eines anderen nach diesem Gesetz geschützten Schutzgegenstandes dürfen ohne Zustimmung des Rechtsinhabers 
nicht umgangen werden. “ Da es in der Regel Verlage (und nicht die Urheber selbst) sind, die solche technischen Schutzmaßnahmen anbringen, sind sie in dieser Formulierung als Rechtsinhaber angesprochen (ebenso in $\S 95 b, c$ und $\S 108 b$ ). $\S 95 \mathrm{c}$ macht dies besonders deutlich, wenn dort in Abs. 2 von „Urheber oder jeden anderen Rechtsinhaber“ gesprochen wird.

In der Fachliteratur wird zur Unterscheidung von „originären oder derivativen [Rechts]Inhabern“ gesprochen. Der Inhaber eines einfachen Nutzungsrechts hat, so (Stieper 2009), “daher nicht die Kompetenz, Nutzungshandlungen Dritter zu genehmigen, und ist damit kein „Rechtsinhaber“ i. S. d. §95a”. Daraus folgert (Stieper 2009): „Als Rechtsinhaber kommen demnach allenfalls die Inhaber ausschließlicher Nutzungsrechte in Betracht." 175 Brinkel $(2006,10)$ weist allerdings darauf hin, dass die Verwendung von „Rechtsinhaber“ außerhalb der 95er-Paragraphen „nicht unproblematisch“ ist. Die Erweiterung der Anwendung von „Rechtsinhaber“ auf kommerzielle Verwerter

verschleiert die unterschiedlichen Interessen der einzelnen Glieder der urheberrechtlichen Verwertungskette [...]. Dies ist vor allem deswegen bedenklich, weil die ursprünglich im Mittelpunkt des urheberrechtlichen Schutzes stehenden Werkschöpfer heute in der Verwertungspraxis eine eher untergeordnete Rolle spielen. Das generalisierende Abstellen auf Rechtsinhaber im Allgemeinen kann diesen Trend verstärken, wenn die rechtlichen Wertungsargumente hauptsächlich auf die „Major-Player“ bei der Verwertung, also vor allem die Produzenten und Hersteller abzielen, ohne hinreichend auf die Interessen der weiteren nach dem Urheberrechtsgesetz Berechtigten Rücksicht zu nehmen.

Trotzdem akzeptiert letztlich auch Brinkel „Rechtsinhaber“ als Oberbegriff für die originären und derivativen Inhaber von Rechten - und nimmt damit die daraus folgende fortschreitende Kommodifizierung und Ökonomisierung von Wissen und Information und der Orientierung des Urheberrechts an den Interessen der Verwerter in Kauf. Zu beachten ist allerdings wohl auch die in InfoSoc 2001 (EG 32) vorgenommene Differenzierung: „A fair balance of rights and interests between the different categories of rightholders, as well as between the different categories of rightholders and users of protected subject-matter must be safeguarded.” Es ist entsprechend nicht angebracht, alle Rechte und Ansprüche, die den Urheber über die Persönlichkeitsrechte hinaus zustehen, auf die Rechte und Ansprüche der Verwerter zu übertragen.

Zurück zur Praxis der Rechtsübertragung: Verwerter partizipieren durch die Vertragsübertragung an den Rechten der Urheber, ohne selbst Autoren von Werken zu sein. Sie schaffen keine Werke, sondern produzieren nur „Werke“ - im

175 (Stieper 2009) Rechtfertigung, Rechtsnatur und Disponibilität der Schranken des Urheberrechts, 452. 
urheberrechtlichen Jargon „Werkstücke“ genannt (vgl. 5.2). Hier werden sie Informationsobjekte genannt. Dass nur Autoren als Urheber/Schöpfer von Werken angesehen werden können und nicht die verwertenden Verleger, hat der BGH noch einmal jüngst eindeutig bestätigt. ${ }^{176} \mathrm{Ob}$ diese primären Rechte auch Geistiges-Eigentum-Rechte sind, wird hier in Frage gestellt (vgl. Kap. 7). Aber auch wenn man einmal bei dieser Terminologie bleibt, sollte ein Anspruch der Verlage auf geistiges Eigentum an den Werken der Urheber durch die vertragliche Übertragung der Verwertungsrechte nicht durch das Urheberrecht begründet werden. ${ }^{177}$

Zur Rechtfertigung der kommerziellen Nutzungsrechte hat sich in den letzten Jahren eine taktisch nachvollziehbare Rhetorik entwickelt. Von Seiten der Verleger und Informations-/Medienunternehmen wird gegenüber der Politik (aber auch gegenüber der Rechtsprechung) immer stärker das Recht der Autoren in den Vordergrund gerückt. Z. B. wird in einem aktuellen, von großen Medienunternehmen ${ }^{178}$ unterzeichneten Brief an die G7-Kultusminister (mit CC an den Präsidenten der EU-Kommission) vom 29.3.2017179 daran erinnert, dass G8 und G20 2011 erklärt hatten: "authors and thinkers must not be deprived of the fruit of their talent". Das gelte weiterhin und verstärkt im digitalen Zeitalter. Umgepolt wird aber tatsächlich der Schutz der Autoren und Denker auf den Schutz des Interesses des „kreativen Sektors“ und der Bedeutung dieses kreativen Sektors auf die allgemeine Volkswirtschaft:

creative sector [...] contributes \$2.25 trillion to the global economy every year. As well as providing tens of millions of highly skilled jobs, we entertain billions of people every day with diverse content and provide vital investment to support sports, the arts, and culture.

Beständig wird dieses transformative Muster von Seiten der Informationswirtschaft in Anspruch genommen. Deutlich ist die Taktik von Seiten der Verlagswirtschaft zu erkennen, sich öffentlichkeitswirksam für die Rechtsansprüche der Urheber, einschließlich deren Vergütungsansprüche, einzusetzen, um in Wirk-

176 BGH Beschluss vom 18. April 20181 BvR 1213/16.

177 Der BGH in Verlegerbeteiligung-Entscheidung von 2016 lässt allerdings die Frage nach einem abgeleiteten Eigentumsanspruch von Verlagen offen: „Es kann offenbleiben, inwieweit das dem Verleger vom Urheber eingeräumte Verlagsrecht als (abgeleitetes) ausschließliches Immaterialgüterrecht dem Schutzbereich des Eigentumsrechts aus Art. 14 Abs. 1 GG und Art. 17 Abs. 1 EU-Grundrechtecharta unterfällt“ (74). Der BGH bejaht diese Frage nicht, aber verneint sie auch nicht.

178 BBC Worldwide, Mediaset, Canal+, Bundesliga, UEFA, 20th Century Fox, Sony Pictures, the Walt Disney Company.

179 Brief an die G7-Kultusminister 29.3.2017 - https://bit.ly/2m5nCYQ. 
lichkeit damit die Ansprüche der Verlagswirtschaft zu sichern. ${ }^{180}$ Der Schutz der Urheber findet, so die wohl berechtigte Annahme, eine größere Akzeptanz in der Öffentlichkeit (und der Politik) als ein erweiterter Schutz der Verlagswirtschaft.

Das Urheberrecht als Recht der Autoren gibt diesen die absolute Verfügung über ihr Recht, also auch über ihre Verwertungsrechte. Zu diesem Recht gehöre, nach (Schack 2015, RN 4), auch, dass es „dem Urheber die freie Entscheidung darüber belässt, ob, wem und zu welchen Bedingungen er anderen die Nutzung eines Werkes erlauben möchte“. Ob es in Bildung und Wissenschaft wirklich immer eine freie Entscheidung der Urheber ist, kann angesichts der Marktstärke der kommerziellen Verwerter, der Verlage, bezweifelt werden. Die Vertragsbedingungen werden oft genug nicht frei zwischen den Vertragspartnern ausgehandelt, sondern durch die Vorgabe der Vertragsdetails quasi erzwungen oder, wenn es gar keinen schriftlichen Vertrag dafür gibt, als gegeben vorausgesetzt. ${ }^{181}$ Gerade jüngere Wissenschaftler, die ihre Karriere auf Publikationen in als hochrangig angesehenen Verlagen aufbauen müssen, haben keine Wahl, zumal es oft genug keine Alternative zu der Zeitschrift xy im Verlag yz gibt.

Fazit. Das Recht der vollständigen Übertragung der Verwertungsrechte durch die primären Rechtsinhaber als Nutzungsrechte an die kommerziellen Verwerter liegt nicht im Interesse der Öffentlichkeit an einer freizügigen Nutzung publizierten Wissens. Es ist nicht angemessen, für die erworbenen Nutzungsrechte der Verlage den gleichen urheberrechtlichen Schutz vorzusehen wie für die originären Verwertungsrechte der Urheber. Es ist fraglich, ob die Prozesse der vertragsgemäßen Übertragung von Rechten von Urhebern an Verlegern überhaupt im Urheberrecht

180 Vgl. (Menard 2012) Urheber: Filter oder Schöpfer? Vgl. Münchner Erklärung der IG Belletristik und Sachbuch: „Wir sind existenziell darauf angewiesen, dass es ein starkes, durchsetzbares Urheberrecht für Schöpfer und Verleger literarischer und sachbezogener Werke gleichermaßen gibt. Nur damit kann die einmalige kulturelle Vielfalt unserer literarischen Landschaft gewährleistet werden.“ - https://bit.ly/3ezVeF9

181 In der Begründung des RegE für das Zweitverwertungsrecht wird auf diese (zu überwindende) Asymmetrie zwischen Urheber und Verleger hingewiesen: „Aufgrund der hohen Marktmacht einzelner Anbieter ist die Situation zwischen den wissenschaftlichen Autoren und den Verlagen vielfach asymmetrisch. Die Verlage geben den Autoren die Publikationsbedingungen vor. Gegenwärtig räumen die Autoren wissenschaftlicher Beiträge daher den Wissenschaftsverlagen vielfach ausschließliche Rechte zur kommerziellen Verwertung ihrer Beiträge ein. Damit verfügen allein die Wissenschaftsverlage über das Recht, diese Inhalte über Onlinemedien zugänglich zu machen.“ - Deutscher Bundestag Drucksache 17/13423 8.5.3013: https://bit.ly/2NouagE. 
(also im Urhebervertragsrecht) geregelt werden muss. Könnten Pflichten und Rechte nicht auch im Schuldrecht des BGH geregelt und damit von ideologischen Auseinandersetzungen um Eigentum bzw. Enteignung von Eigentum befreit werden? Der gesamte Vorgang der Rechteübertragung an kommerzielle Verwerter ist auch Beleg für die These der Kommodifizierung und daraus folgenden Ökonomisierung von Wissen und Information auch in Bildung und Wissenschaft. Ob die Überlassung von Nutzungsrechten in den Bereichen Bildung und Wissenschaft wirklich gänzlich („ob, wem und zu welchen Bedingungen“) in der Entscheidung des Urhebers sein soll, kann bezweifelt werden. Das kann nicht im Interesse der Allgemeinheit liegen und fördert nicht das Allgemeinwohl und die Sicherung des kulturellen Erbes. Angesprochen ist damit, dass die die Urheber unterstützenden und finanzierenden Institutionen ein Mitspracherecht bei der Rechteübertragung an kommerzielle Verwerter haben sollten. Das wird in 11.3.6 am Beispiel des Zweitverwertungsrechts bzw. dessen Mandatierung unter dem Konzept eines institutionellen Rechts diskutiert.

\subsection{Das Problem mit den Schranken}

Schrankenregelungen sind keine Wohltaten, sondern Rechte, „gesetzlich erlaubte Nutzungen“. Das wird seit 2018 auch im UrhG bei dem Abschnitt zu den Schrankenregelungen explizit formuliert. Das hindert aber nicht, dass Schranken weiterhin als Ausnahmen bzw. Einschränkungen (exceptions and limitations) von den exklusiven, umfassenden Verwertungsrechten der Rechtsinhaber verstanden werden. Das „exklusiv/umfassend“ muss aber nicht wortwörtlich verstanden werden. Das BVerfG hat klargestellt, dass die Verwertungsrechte durch das Recht zwar „zunächst als umfassend formuliert“ werden ${ }^{182}$; dass sie dann aber vom Gesetzgeber in Schrankenregelungen konkret normiert, d. h. zugunsten einer genehmigungsfreien Nutzung relativiert werden. Das ist das Ergebnis der Schranken. Dafür hat der Gesetzgeber einen breiten Spielraum, und nichts spricht dafür, dass er dabei zwingend auf einen ausbalancierten Kompromiss zwischen den verschiedenen Interessen der Akteursgruppen abzielen muss. Darauf gehen wir mit Blick auf das Wissenschaftsurheberrecht insgesamt in 6.8.1 näher ein.

Derzeit ist die Rechtsprechung überwiegend der Ansicht, dass Schranken möglich eng angelegt sein, also die Rechte der Urheber nur so wenig wie möglich

182 BVerfG, 25.10.1978 - 1 BvR 352/71 (GRUR 1980, 44), Zitat (40). 
eingeschränkt werden sollten. ${ }^{183}$ Dem hat sich auch der Gesetzgeber angepasst. Verantwortlich dafür ist vor allem der Drei-Stufen-Test, der allgemein als (negative) Schranken-Schranke (also als Begrenzung) der Schrankenbestimmungen angesehen wird (ausführlich dazu in 6.9). Schranken sind also nicht nur Einschränkungen der exklusiven Rechte der Rechtsinhaber aus öffentlichem Interesse, sondern auch quantitative, qualitative und technische Einschränkungen der freien Nutzung in Bildung und Wissenschaft, welche auch im öffentlichen Interesse liegt.

Quantitative Beschränkungen sind z. B. Nutzungserlaubnisse nur für kleine Teile bzw. $15 \%$ eines Werks: Qualitative Beschränkungen sind z. B. Verbote von Annexhandlungen wie Drucken oder Speichern von angesehenen Werken. Technische Beschränkungen sind z. B. das Verbot des externen Zugriffs auf elektronische Angebote der Bibliothek.

Solche quantitativen Einschränkungen gelten nicht für die in vielen wissenschaftlichen Fächern zentrale Textsorte der Zeitschriftenartikel. Diese können in vollem Umfang genehmigungsfrei genutzt werden - das war schon in §52a aus der ersten Urheberrechtsreform von 2003 so vorgesehen und gilt auch weiter über §60c im UrhWissG von 2017/18. Die Vergütungsverpflichtung besteht aber auch hier - bislang geregelt über Gesamtverträge zwischen den Trägern der wissenschaftlichen Einrichtungen und der jeweiligen Verwertungsgesellschaft. ${ }^{184}$ Für Artikel aus Zeitungen bzw. Zeitschriften der allgemeinen Presse gilt die in den betreffenden Schranken geregelte genehmigungsfreie Nutzung seit 2018 nicht mehr. Durch intensives Lobbying der Me-

183 In der Rechtswissenschaft wird die Ansicht, dass urheberrechtliche Schrankenbestimmungen als Ausnahmen eng auszulegen sind, nicht vergleichbar durchgängig geteilt. Thomas Dreier z. B. teilt nicht diese Ansicht, sondern schätzt Schranken als „ein notwendiges Instrument zur Bestimmung des optimalen Zuschnitts der ausschließlichen Rechtsbefugnisse von Urhebern und Rechtsinhabern [ein], deren Auslegung davon abhängt, wieweit die ausschließlichen Rechtsbefugnisse der Rechtsinhaber eingeschränkt sein müssen, um das rechtspolitisch angestrebte Optimum zu erreichen.“ (Dreier 2019b) Dreier stellt in diesem Aufsatz sogar die grundlegendere Frage, ,inwieweit die Besonderheiten von Wissenschaft - als Handlungen im Rahmen von Lehre und Forschung, zum Zwecke von Text- und Data-Mining sowie zur Aufgabenerfüllung der Kultureinrichtungen - besondere urheberrechtliche Regelungen rechtfertigen.“ Ein „ob“ allerdings bejaht er nach wie vor, für das ,inwieweit“ legt er sich nicht fest.

Im Schlusskapitel dieser Arbeit wird das „ob“ tendenziell verneint. Anstelle des Systems der Schranken reichte für das Wissenschaftsrecht eine allgemeine Klausel zur Regelung der Nutzungsund Freiheitsrechte aus.

184 Auf der Website des dbv werden die auf das Urheberrecht bezogenen Verträge und Vereinbarungen nachgewiesen - https://bit.ly/2Rs2Kqy, darunter die zu den neuen $\S \S 60 \mathrm{a}, 60 \mathrm{c}$ und 60e sowie der Gesamtvertrag Vervielfältigungen an Schulen. Näheres dazu in den Abschnitten 13.2.1-13.2.5 sowie 13.7.2. 
dienwirtschaft bzw. großer Zeitungen wie FAZ wurde das im Rahmen des UrhWissG aus den entsprechenden Schrankenbestimmungen herausgenommen. Nicht über das Urheberrecht, sondern 2018 über einen Gesamtvertrag (also letztlich über eine Lizenzvereinbarung) wurde zumindest die (gebührenpflichtige) Nutzung von Zeitungsartikeln in Schulen geregelt (vgl. FN 526 und 527).

Die quantitativen Einschränkungen in den Schranken gelten vor allem für die Nutzung von Büchern. Zwar werden Monographien und Sammelbände in allen wissenschaftlichen Disziplinen erstellt und genutzt, aber es sind vor allem die Geistes- und Sozialwissenschaften im weiteren Sinn, bei denen diese Textsorten eine immer noch große Rolle spielen. In diesem Segment des Informationsmarktes sind in Deutschland viele kleinere Verlage aktiv - kleiner im Vergleich zu den großen Verlagskonsortien auf den Zeitschriftenmärkten -, die das deutsche Urheberrecht schützt. Auch die Konflikte zwischen Bibliotheken und Verlagen (vgl. 10.1.3 und 10.1.4) bezogen sich in erster Linie auf die Nutzung von Büchern, insbesondere von auf Lehren und Lernen bezogenen Büchern - gemäß den Schrankenregelungen in den $\S \S 52 \mathrm{a}$ und 52b. Bei den Zeitschriften deutet sich an (vgl. die Vereinbarungen durch DEAL in 14.8), dass die neue Leitidee der Nutzungsfreiheit nach Open-Access-Prinzipien von den kommerziellen Verlagen akzeptiert werden kann allerdings unter der Voraussetzung, dass die Öffentlichkeit bereit ist, die Erstellung der Informationsobjekte durch die Verlage zu finanzieren. Bei den Büchern gibt es bislang noch keine vergleichbaren Vereinbarungen. Wird es sie in der Zukunft geben, dann gäbe es auch keinen Grund mehr für Schrankenregelungen mit stark eingeschränkten Nutzungserlaubnissen (ausführlicher am Ende von 14.8 und in 14.4.3).

In der nationalen und europäischen Tradition besteht aber bislang die Tendenz, das Ausmaß der erlaubten bzw. untersagten Nutzungen in den einzelnen Normen des Urheberrechts so genau wie möglich festzulegen - um Rechtsunsicherheit zu vermeiden. Erkauft wird das oft entweder durch Hyperkomplexität der Normen oder durch eine entwicklungsfeindliche Abgeschlossenheit der Anzahl der Normen in der Orientierung am Status quo. Beispiel für Ersteres ist im deutschen UrhG der (weitgehend unverständliche, da überkomplexe) $§ 53$ (Privatkopie). Beispiel für Letzteres ist in der InfoSoc-Richtlinie der EU von 2001 der Versuch bzw. die verbindliche Vorgabe, die Anzahl der zugelassenen Schranken vollständig und damit abschließend aufzulisten - und zwar in Artikel 5 Abs. 3 a-o. Sowohl eine zu detaillierte Regelung im Einzelfall als auch eine Regelung mit Vollständigkeitsanspruch für erlaubte Schranken sind wenig entwicklungsoffen.

Der Gesetzgeber nimmt seinen Spielraum für die Gestaltung der Schranken oft nur durch Verwendung unbestimmter Rechtsbegriffe wahr (vgl. dazu 3.2 Rechtssicherheit und Zukunftsoffenheit). Dabei wird „geboten“ und „angemessen“ beson- 
ders häufig für die Gestaltung von Schranken verwendet. Das sind offensichtlich die Begriffe, die am meisten auslegungsbedürftig, aber auch auslegungsfähig sind. ${ }^{185}$ Vor allem „zu dem jeweiligen Zweck geboten“, aber auch „gerechtfertigt“" ist an den jeweiligen Zweck gebunden, nicht an externe Vorgaben. ${ }^{186}$ In einem Alltagsverständnis von Sprache klingt das „zu dem jeweiligen Zweck geboten“ vernünftig vielversprechend. ${ }^{187}$ Man dürfe, so die spontane Interpretation dieser Formulierung, urheberrechtlich geschützte Werke in dem Ausmaß vervielfältigen und öffentlich zugänglich machen, wie es der aktuelle Bedarf in der wissenschaftlichen Forschung oder für die „Veranschaulichung des Unterrichts“ erforderlich macht (das wäre der gebotene Zweck). Im Extremfall: Wird ein ganzes Buch gebraucht, z. B. um einen Kollegen in einer Arbeitsgruppe wegen einer anstehenden Rezension dieses Buches um Rat zu bitten, dann sollte dieses vervielfältigt oder auf den Server für den Zugriff der Forschungsgruppe

185 „Geboten“ wird im Urheberrecht an verschiedenen Stellen verwendet; einige Beispiele: In $\S 50$ (Berichterstattung über Tagesereignisse): „Vervielfältigung, Verbreitung und öffentliche Wiedergabe von Werken, die im Verlauf dieser Ereignisse wahrnehmbar werden, in einem durch den Zweck gebotenen Umfang zulässig“; $§ 51$ (Zitate): „Zulässig ist die Vervielfältigung, Verbreitung und öffentliche Wiedergabe, wenn in einem durch den Zweck gebotenen Umfang... “; in §52a (Öffentliche Zugänglichmachung für Unterricht und Forschung) Abs. 1: „öffentlich zugänglich zu machen, soweit dies zu dem jeweiligen Zweck geboten ist“; in $\S 53$ (Privatkopie) Abs. 2, 1: „zum eigenen wissenschaftlichen Gebrauch, wenn und soweit die Vervielfältigung zu diesem Zweck geboten ist“; $§ 53$ Abs. 2 S. 2: „zur Aufnahme in ein eigenes Archiv, wenn und soweit die Vervielfältigung zu diesem Zweck geboten ist und als Vorlage für die Vervielfältigung ein eigenes Werkstück benutzt wird“; $§ 53$ Abs. 3 S.1 und 2: „Vervielfältigungsstücke von kleinen Teilen eines Werkes ... 1. im Schulunterricht, in nichtgewerblichen Einrichtungen der Aus- und Weiterbildung sowie in Einrichtungen der Berufsbildung in der für eine Schulklasse erforderlichen Anzahl oder 2. für staatliche Prüfungen und Prüfungen in Schulen, Hochschulen, in nichtgewerblichen Einrichtungen der Aus- und Weiterbildung sowie in der Berufsbildung in der erforderlichen Anzahl herzustellen oder herstellen zu lassen, wenn und soweit die Vervielfältigung zu diesem Zweck geboten ist.“

186 In der Begründung des RefE für §52a UrhG vom 6.11.2002, die auch für die endgültige und im Bundestag verabschiedete Version gilt, heißt es dazu: „Aus den Vorgaben der Richtlinie [InfoSoc von 2001 - RK] ergibt sich die zwingende Beschränkung, dass die Zugänglichmachung zu dem jeweiligen privilegierten Zweck geboten und zur Verfolgung nicht kommerzieller Zwecke gerechtfertigt sein muss. Vergleichbare Beschränkungen sieht das bestehende Recht bereits in $\S 53$ Abs. 2 Nr. 1 bzw. $§ 53$ Abs. 3 vor, also den entsprechenden Schranken zugunsten von Wissenschaft und Unterricht im Bereich des Vervielfältigungsrechts“.

187 Aber die Semantik der Fachsprache ist nicht immer die der Umgangssprache, wie man ja auch an der Verwendung von „öffentlich“ in der „öffentlichen Zugänglichmachung“ entsprechend §19a UrhG lernen musste, wo „öffentlich“ nicht unbedingt das ist, was in der Verwendung der Umgangssprache vermutet werden kann - nämlich „öffentlich“ für jedermann und ohne Raumund Zeitbeschränkung. 
gelegt werden dürfen. Dem ist aber nicht so. „Geboten“ wird in Rechtsetzung und Rechtsprechung gerade nicht an den Zweck gebunden, sondern in der Regel durch Vorgaben wie durch unionsrechtliche Richtlinien oder durch urheberrechtlich einschlägige internationale Verträge und Vereinbarungen (wie TRIPS/WTO durch die WIPO). Konkret orientiert sich das „geboten“ insbesondere am DreiStufen-Test oder an dem auch vom BVerfG immer wieder geforderten Interessenausgleich.

Das ist also das eines der grundlegenden Probleme mit den Schranken. Die starke Orientierung an den Vorgaben, die aber in ganz anderen Umgebungen entstanden sind als sie heute sich entwickelt haben, führt bis heute (also auch noch im UrhWissG von 2017/18) zu Schrankenregelungen, welche die Arbeit in Bildung und Wissenschaft eher behindern als dass sie sie befördern. Dies könnte verhindert werden, wenn
(a) die unionsrechtlichen oder anderen internationalen Vorgaben kreativer und der Gegenwart angemessen ausgelegt würden;
(b) beim Interessenausgleich dem stärkeren Interesse der Öffentlichkeit an einer freizügigen Nutzung von Wissen und Information mit einer Gewichtung Rechnung getragen würde;
(c) der Drei-Stufen-Test, wie es später in 6.9 vorgeschlagen wird, nicht nur liberaler interpre- tiert, sondern gänzlich neu gefasst würde (oder gleich ganz als Kriterium für Erlaubnishand- lungen in Bildung und Wissenschaft gestrichen würde).

All das wird schwierig zu realisieren sein. Aber ohnehin reicht das nach der hier vertretenen Einschätzung nicht aus. Das grundsätzliche Problem besteht daran, dass der Gesetzgeber meint vorschreiben zu können bzw. zu müssen, in welchem Umfang es für die Akteure in Bildung und Wissenschaft erlaubt sein soll, veröffentlichtes Wissen genehmigungsfrei zu nutzen. Die Beschränkung des Zugriffs auf publizierte Wissensobjekte, zumal wenn diese ohnehin schon rechtmäßig in der Bibliothek als Informationsobjekte vorhanden sind, ist ein starker Eingriff in die Wissenschaftsfreiheit. Ein Teil von Wissenschaftsfreiheit - sozusagen die Voraussetzung für Forschung und für hochwertige Ausbildung - ist auch das Recht, Informationsobjekte in dem Ausmaß zu nutzen, wie es für diese Zwecke erforderlich ist. Informations- und Wissenschaftsfreiheit sind, so wird man das GG verstehen dürfen, höhere Rechte als individuelle Eigentumsrechte bzw. nicht eingeschränkte Rechte. Eigentum wird im Anspruch durch „Eigentum verpflichtet“ (Art. 14 Abs. 2 Satz 1) relativiert - Informations- und Wissenschaftsfreiheit werden im GG nicht durch eine vergleichbare Einschränkung relativiert. Der Zweckbegriff für wissenschaftliche und bildungsbezogene Nutzung muss universal verstanden werden. Es gehört zur Wissenschaftsfreiheit entscheiden zu dürfen, was für die Forschung und für die Lehre gebraucht wird. In diese Entscheidung sollte der Gesetzgeber nicht eingreifen. 
Für den Gesetzgeber war für eine kurze Zeit das Fenster offen, sich alleine an dem Zweck der Nutzung zu orientieren. Im Koalitionsvertrag der Großen Koalition von 2003 war vorgesehen, in das UrhG eine allgemeine ABWS einzuführen (vgl. 12.1). Das Konzept der ABWS sollte sich alleine an dem nicht weiter zu spezifizierenden Zweck der Nutzung in Forschung und Lehre, Wissenschaft und Bildung orientieren. Das hätte das bisherige Urheberrecht vereinfacht und verkürzt und beschränkte nicht mehr das, was als Nutzung unbeschränkt sein sollte. Schrankenregelungen, so wie sie jetzt als kleinteilige Einschränkungen und Ausnahmen verstanden und ausgeführt werden, sind für das Wissenschaftsurheberrecht nicht nützlich.

Schließlich - das dritte grundlegende Problem mit den Schranken - orientieren sich die derzeit geltenden Schrankenregelungen, einschließlich diejenigen des gerade erst eingeführten UrhWissG, an dem monistischen Prinzip des Urheberrechts (vgl. 6.5). Entsprechend wird in so gut wie allen Schrankenregelungen den vermögensrechtlichen Interessen der Rechtsinhaber (Urheber und Verwerter) Rechnung getragen. Die Schrankenregelungen erlauben nicht nur die genehmigungsfreie Nutzung, sondern schreiben für die Nutzung i.d. R., sozusagen zur Kompensation der Einschränkung der Rechte, eine Vergütungsverpflichtung vor. Das ist in zweifacher Hinsicht problematisch. Zum einen hat Verwertung, wie schon erwähnt, in der Wissenschaft nicht eine kommerzielle Konnotation (Verwertung ist in erster Linie „Veröffentlichung“). Daher spielt Vergütung hier so gut wie keine Rolle (dazu ausführlich in Kap. 8). Für Wissenschaftler zählt die reputative, nicht die monetäre Anerkennung. Zum anderen setzt sich bei den Verwertern die Einsicht durch, dass die Geschäftsmodelle sich nicht mehr durch Einnahmen aus der Nutzung finanzieren lassen. In dem sich abzeichnenden OpenAccess-Paradigma des Publizierens sind der Zugriff auf und die Nutzung von Informationsobjekten grundsätzlich frei (libre et gratuit), auch für Zwecke, die beim Publizieren nicht vorgesehen waren. Zwar werden noch für eine längere Zeit kommerzielle Materialien aus der Vor-Open-Access-Zeit genutzt, auf die urheberrechtliche Regelungen angewendet werden (müssen). Aber es wäre nicht zu viel verlangt gewesen, dass eine Reform des Urheberrechts 2017/218 sich mehr an Gegenwart und Zukunft hätte orientieren sollen als an einer Fortschreibung des Status quo.

Fazit. Schranken sind eine unglückliche und unpassende Regulierungsform im Urheberrecht. Außerhalb der Rechtswissenschaft versteht niemand, dass durch Schranken gerade die Nutzung geregelt werden soll. Schranken (im Bild der Schrankenmetapher) sind wohl eher geschlossen als offen. Gerade bei den Schranken ist Einiges im Urheberrecht falsch gelaufen. Schranken greifen nach hier vertretener Auffassung ungebührlich in Wissenschaftsfreiheit ein, indem sie vorschreiben, in 
welchem Ausmaß das publizierte Wissen genutzt werden darf. Die Regelungen bei den Schranken setzen über die Vergütungsverpflichtung vermögensrechtliche Interessen bei den Akteuren in Bildung und Wissenschaft voraus, die zumindest in der öffentlich finanzierten Wissenschaft nicht vorhanden sind. Schließlich sind Schrankenregelungen angesichts des sich deutlich abzeichnenden allgemeinen Paradigmas der freien Nutzung in Bildung und Wissenschaft keine zukunftsorientierten Urheberrechts-Regelungen. Wenn auch die Informationsökonomie der Verlagswirtschaft ihren Return of investment nicht mehr an die aktuelle Nutzung bindet, sondern an der Erstellung und Verbreitung der Informationsobjekte, sollte der Gesetzgeber Schrankenregelungen nicht als sehr eingeschränkte Nutzungen normieren bzw. sie besser und dem entwickelten Zeitgeist entsprechend ganz aufgeben.

\subsection{Ein selbständiges Wissenschaftsurheberrecht}

Was in dem zu Anfang dieses Kapitels zitierten Sammelband (Dreier/Hilty 2015) mit Blick auf das Urheberrecht insgesamt problematisiert wird, gilt erst recht für das Wissenschaftsurheberrecht. Im ,alten Haus“ von 1965, aber auch im TRIPS-Vertrag und im WIPO-WTC spielt Wissenschaft kaum eine Rolle, schon gar nicht eine hoch angesiedelte Rolle. Auch in InfoSoc 2001 wird nur an einer einzigen Stelle (in Art. 5, 3, a) auf „teaching or scientific research”188 eingegangen. Diese (bis heute gültige) Schranke ließe den nationalen Gesetzgebern allerdings einen breiten Spielraum. Selbst die EU-Kommission ${ }^{189}$ weist mit Hinweis auf eine von ihr in Auftrag gegebene Studie darauf hin, dass Einschränkungen (wie im deutschen UrhG bei §52a) durch die Schranke InfoSoc 2001 Art. 5, 3, a nicht zwingend sind:

The open-ended content of [this exception] left ample manoeuvre for the Member States to enact the conditions under which the exception could be enjoyed. Nothing prevents domestic laws to further define the beneficiaries, the types and quantities of works that can be used, as well as the type of use. ${ }^{190}$

188 Aus Art. 5 Abs. 3 lit. a: “a) use for the sole purpose of illustration for teaching or scientific research, as long as the source, including the author's name, is indicated, unless this turns out to be impossible and to the extent justified by the non-commercial purpose to be achieved"; vgl. die Erläuterungen 34 und 42 von InfoSoc 2001.

189 COMMISSION STAFF WORKING DOCUMENT IMPACT ASSESSMENT on the modernisation of EU copyright rules (Brussels, 14.9.2016 SWD (2016) 301 final). Accompanying the document Proposal for a Directive of the European Parliament and of the Council on copyright in the Digital Single Market. Part 2/3.

190 (Triaille et al. 2013) Study on the application of Directive 2001/29/EC on copyright ..., p. 38. 
Dieser Spielraum, quasi die Steilvorlage der EU, wurde aber bis heute nicht, auch nicht in Deutschland, umfassend für ein Wissenschaftsurheberrecht genutzt. ${ }^{191}$ Dies zeigt deutlich, dass das in der deutschen Politik ständig verwendete Argument, an die europäischen Vorgaben gebunden zu sein, oft nur eine Schutzbehauptung in Ermangelung kreativen Auslegungswillens ist. An Urheberrechtsregelungen für Bildung und Wissenschaft sind keineswegs die gleichen Maßstäbe anzulegen wie an die für die allgemeinen Publikumsmärkte. Hier einige Argumente dafür aus den vorangegangenen Abschnitten:

(1) Das dem Urheberrecht zugrundeliegende Konzept des individuellen Schöpfers ergibt in der Praxis keinen Sinn - auch wenn es in den verschiedenen Fächern bzw. Wissenschaftsgebieten Unterschiede in der Extension des kollaborativen Arbeitens und der Vielfachautorenschaft gibt.

(2) Die exklusive Bindung der Urheberrechte an den/die individuellen Autoren ist angesichts ihrer hohen Anbindung an und der Abhängigkeit an die sie tragenden Institutionen nicht zu vertreten. Diese stellen die vielfältigen Ressourcen für die Arbeit der Akteure in Bildung und Wissenschaft bereit, und sie sind es, die im Interesse der Öffentlichkeit das kulturelle Erbe nachhaltig sichern sollen.

(3) Entsprechend ist nicht zu vertreten, dass Urheber in Bildung und Wissenschaft ihre Verwertungsrechte vollständig als Nutzungsrechte an kommerzielle Verwerter übertragen, ohne dass die sie tragenden Institutionen ein Mitspracheoder sogar ein eigenes institutionelles Recht an den Werken haben.

(4) Die Akteure in Bildung und Wissenschaft sind i.d. R. nicht darauf angewiesen, dass sie ihren Lebensunterhalt über Einnahmen aus ihren Werken erzielen.

(5) Verwertung hat in der Wissenschaft nicht die kommerzielle monetäre Konnotation, sondern bedeutet in erster Linie „Veröffentlichung“. Entsprechend ist die Währung in Bildung und Wissenschaft nicht monetäre, sondern reputative Anerkennung.

(6) In Bildung und Wissenschaft führt die Verknappung der Nutzung (z. B. über die Preispolitik der kommerziellen Verwerter) zu einer unerwünschten Unternutzung. Es ist das primäre Interesse jedes wissenschaftlichen Autors, dass seine Werke so intensiv wie möglich von anderen genutzt werden.

Trotz der deutlichen Unterschiede, wie in Wissenschaft einerseits und auf den Publikumsmärkten andererseits die Prozesse von Produktion, Verbreitung und

191 Verschiedentlich wurde Art. 5 Abs. 3 sogar schon als „allgemeine Bildungs- und Wissenschaftsschranke“ bezeichnet - so von (Raue 2019) Rechtssicherheit für datengestützte Forschung. Das hätte der Gesetzgeber so als eine ABWS übernehmen können. Hat er aber nicht (vgl. die Diskussion zur ABWS in Kap. 11.4). 
Nutzung von Wissen und Information sich herausgebildet haben, hat sich kein selbständiges Wissenschaftsurheberrecht entwickelt. Die Einheit des Urheberrechts wird von der Rechtswissenschaft überwiegend als unabdingbar angesehen. „Wissenschaftsurheberrecht“ ist zwar in der Fachliteratur nicht unüblich; ${ }^{192}$ aber das ist wohl mehr ein Etikett als ein verselbständigter Bereich des Urheberrechts. Mit „Wissenschaftsurheberrecht“ wird vom Gesetzgeber eher das Ensemble der auf Bildung und Wissenschaft bezogenen Schrankenregelungen verstanden. Dieses Ensemble hat der Gesetzgeber in Deutschland mit dem UrhWissG 2017 neu bestimmt, und zwar in dem „Unterabschnitt 4 Gesetzlich erlaubte Nutzungen für Unterricht, Wissenschaft und Institutionen“. Er hat dabei aber die Bezeichnung „Wissenschaftsurheberrecht“ vermieden. Vielmehr spricht die Begründung für das UrhWissG von der „rechtspolitischen Maßgabe, eine sogenannte Bildungs- und Wissenschafts-Schranke zu schaffen“. Man könnte das sozusagen als Schwundstufe eines umfassenden und selbständigen Wissenschaftsurheberrechts als die Gesamtheit der Regelungen im Urheberrecht verstehen. Umfassend ist das nicht. Das Wissenschaftsurheberrecht alleine auf die Schrankenregelungen zu reduzieren, wird den Anforderungen in Bildung und Wissenschaft nicht gerecht.

\subsubsection{Balance im Wissenschaftsurheberrecht als quasi gleichschenkeliges Dreieck?}

In so gut wie allen juristischen Texten, in den Begründungen für Gesetzesvorhaben und in der Politik, wird als Ziel der Urheberrechtsregulierung ein ausgewogener Interessenausgleich in der Trias zwischen den Urhebern, den Verwertern und den Nutzern angesehen. Diese auf das gesamte Urheberrecht bezogene Trias wird auch auf das Wissenschaftsurheberrecht bezogen. ${ }^{193}$ Hier nur ein Beispiel für dieses quasi gleichschenklige Dreieck aus der bislang letzten Urheberrechtsreform von 2017/18: Am 13. Juni 2017 in der kritischen Endphase der Reform für ein neues „Wissenschaftsurheberrecht“ (das sogenannte UrhWissG ${ }^{194}$ ) betonte der damalige Minister für das Bundesministerium der Justiz und für Verbraucherschutz, Heiko Maas, in einer Rede ${ }^{195}$ vor der Hauptversammlung des Börsenvereins des Deutschen

192 Z. B. (Bajon 2010) Interessenausgleich im Wissenschaftsurheberrecht?

193 (Sattler 2009) Der Status quo der urheberrechtlichen Schranken für Bildung und Wissenschaft: „Dem Gesetzgeber obliegt es, mittels der urheberrechtlichen Schranken zwischen [den „widerstreitenden Interessen von Nutzern und Rechtsinhabern”] eine ausgewogene Balance zu schaffen.“ 194 Das „W“ steht im UrhWissG aber nicht für Wissenschaft, sondern für Wissensgesellschaft. 195 Rede Heiko Maas Hauptversammlung des Börsenvereins des Deutschen Buchhandels, 13.6.2017: https://bit.ly/2m6f6cd. 
Buchhandels den „Ausgleich unterschiedlicher Belange“. Das klingt zunächst plausibel. Irritierend allerdings, wie Maas die Trias bzw. den „Ausgleich“ sieht. Er stellt „die Rechte von Autoren und Verlagen“ (als ersten Teil der Trias) den „Interessen der Nutzer“ (als zweiten Teil der Trias) gegenüber (und benennt als Dritten im Bunde die „Bildungseinrichtungen und ihre Träger, die das deutsche Bildungssystem finanzieren“).

Dabei mag es etwas ungewöhnlich sein, die Interessen der Bildungseinrichtungen (einschließlich der ihnen zuarbeitenden Vermittlungsorganisationen wie Bibliotheken) mit denen der sie finanzierenden Träger in dem dritten Teil der Trias des Urheberrechts zusammenzufassen. Aber das kann sogar die Diskussion belebend sein. Beide, die Einrichtungen und ihre Träger, sollten ein Wort bei der Festlegung der Extension der Rechte der Urheber und Verwerter bzw. der Übertragung von Rechten ein Wort mitreden dürfen (vgl. 6.6). Vielleicht ist die Maas'sche Festlegung - vermutlich entgegen seiner Intention - dahingehend zu interpretieren, das individuelle Urheberrecht durch ein institutionelles Urheberrecht zu erweitern. Diese Erweiterung wird hier, insgesamt für das Urheberrecht und speziell bei der Diskussion eines mandatorischen Zweitverwertungsrechts, für richtig angesehen (vgl. 11.3.6).

Die Maas'sche Anordnung und Gegenüberstellung der beiden ersten Teile der Trias ist aber höchst problematisch: Zum einen werden die Interessen der Autoren als Rechte angesprochen und die Rechte der Nutzer bloß als Interessen. Es wird kein vernünftiges Urheberrecht entstehen, wenn die Interessen für die Nutzung nicht auch als Rechte der Nutzung angesehen werden - als fester Bestandteil der Rechte der Autoren. Man kann es auch so sagen: Zum Recht eines Autors gehört sein Recht, zugleich Nutzer zu sein. Wissenschaftliches Arbeiten ist immer schon abhängig von den Vorarbeiten Anderer. Der „kreative Schöpfer“ ist auch der kreative Nutzer. Kein Wissenschaftler kann produktiv tätig werden, ohne auf dem Stand des publizierten Wissens aufzusetzen. Keine Lehrveranstaltung kann geplant und mit Erfolg durchgeführt werden, wenn nicht eben dieser Stand berücksichtigt wird. So wie Wissenschaft unbestritten die Einheit von Forschung und Lehre ist, so sind Autor und Nutzer nicht zu trennen. Wissen sozusagen aus dem Nichts schaffen, geht nicht. In der Wissenschaft sind die Rechte der Nutzer auch Rechte der Autoren.

Problematischer noch, dass Maas die Rechte von Autoren und die Rechte der Verlage als quasi gleichberechtigt in der ersten Trias zusammenfasst. Von einem gleichsam gleichschenkeligen (gleichberechtigten) Dreieck zwischen Urheber, Verwerter und öffentlichem Interesse an der Nutzung veröffentlichen Wissens sollte mit Blick auf Bildung und Wissenschaft nicht die Rede sein. Zumindest müsste im Wissenschaftsurheberrecht dem öffentlichen Interesse an einer umfassenden Nutzung von Wissen und Information aus der Wissenschaft höhere 
Priorität gegenüber dem Verwertungsinteresse durch Verlage/Content Provider eingeräumt werden. Dieser Priorisierung trägt das Urheberrecht nicht Rechnung. Das Urheberrecht versucht vielmehr den unterschiedlichen Interessen und normativen Begründungen für den Umgang mit Wissen und Information dadurch gerecht $\mathrm{zu}$ werden, dass es einen Ausgleich, balancierende Kompromisse zwischen den interessegeleiteten Erwartungen der verschiedenen Akteursgruppen anstrebt. Dieses Ausgleichsprinzip passt nicht für Bildung und Wissenschaft. Mit der hier vertretenen Prioritätsthese wird ein anderer Ansatz verfolgt.

Das politisch seit vielen Jahren, seit dem Zweiten Korb der Urheberrechtsreform (vgl. 5.6.4) immer wieder vertretene Ziel eines ,wissenschaftsfreundlichen Urheberrechts“ kann nur dadurch erreicht werden, dass die verschiedenen Interessen gewichtet werden. Das ist auch nicht unbillig und schon gar nicht realitätsfern. Es ist kein Risiko davon auszugehen, dass ein öffentlicher Konsens darüber besteht, die Interessen der in Bildung und Wissenschaft Tätigen und die Interessen der Gesellschaft an freizügiger Nutzung von Wissen insgesamt höher zu gewichten als die Interessen der Institutionen, die die überwiegend in öffentlichen Umgebungen geschaffenen Wissensobjekte kommerziell über ihre Informationsprodukte und -dienstleistungen verwerten. Das heißt nicht, dass die kommerziellen Interessen überhaupt nicht berücksichtigt werden sollen, aber sie bedürfen einer besonderen Rechtfertigung. Wenn schon eine Balance, ein Ausgleich als Ziel der Urheberrechtsregulierung angestrebt wird, dann sollte das also eine gewichtete Balancierung zugunsten des öffentlichen Nutzungsinteresses sein. Das bisherige „Wissenschaftsurheberrecht“ setzt jedoch diese Priorität nur sehr unzureichend um. In der Begründung für das UrhWissG wird zwar von dem „fairen Interessenausgleich zwischen den Rechtsinhabern und Nutzern“ als „wesentliche Maxime des Urheberrechts“ gesprochen. Aber aus den dem Zitat folgenden Satz in der Begründung wird deutlich, dass auch der „faire Interessenausgleich“ nicht zwingend auf einer gleichen Gewichtung der Interessen beruhen soll.

Im Einklang mit einer entsprechenden und sogar etwas weitergehenden Formulierung in der Präambel des WIPO Copyright Treaty (WCT) von $1996^{196}$ bestehe für die Bundesregierung die „Notwendigkeit ein Gleichgewicht zu wahren zwischen den Rechten der Urheber und dem umfassenderen [fett - RK] öffentlichen Interesse, insbesondere in Bildung und Forschung“. Der Komparativ stellt das stärker zu beachtende Gewicht des öffentlichen Interesses heraus. Wenn schon dieses Interesse gegenüber den Urhebern stärker zu gewichten ist, dann ist der

196 In der Präambel von WIPO heißt es: ,the need to maintain a balance between the rights of authors and the larger public interest, particularly education, research and access to information“ (https://bit.ly/2m5j9Fz). Explizit ist hier auch „access to information“ erwähnt. 
oben vertretene Schluss wohl erlaubt, dass das öffentliche Interesse auch höher zu bewerten ist als eine urheberrechtliche Sicherung der vertraglich abgeleiteten Rechte und Interessen der kommerziellen Verwerter. ${ }^{197}$ Nur müsste diese Einsicht dann auch stärker urheberrechtsreal umgesetzt werden. Tatsächlich begünstigen die Einschränkungen, wie sie in den meisten auf Bildung und Wissenschaft bezogenen Schrankenregelungen vorgenommen werden, den kommerziellen Erfolg der Verwerterindustrien. Das ist die reale, hier nicht für richtig gehaltene Priorität im angeblich dreischenkligen gleichgewichtigen Dreieck.

Fazit. Der Interessenausgleich, die Balance als Ziel der Urheberrechtsgesetzgebung, war, so (Bajon 2010, 22), sozusagen die alte „Leitidee“ des Urheberrechts. Leitideen verändern sich im öffentlichen Diskurs, und alte Leitideen werden dysfunktional, wenn deren Annahmen nicht mehr den sich veränderten Rahmenbedingungen gerecht werden. Die Balance im Interessenausgleich der beim Wissenschaftsurheberrecht beteiligten Akteursgruppen sollte eine gewichtete Balance sein, durch die das kommerzielle Interesse nicht verneint, aber gegenüber dem öffentlichen Interesse und denen von Autor und Nutzer hintangestellt wird.

\subsubsection{Reputationssteigerung durch vergütete Verwertung?}

Im Vergleich mit den Publikumsmärkten bestehen in Bildung und Wissenschaft ganz andere Schutz- und Nutzungs-/Verwertungssinteressen. Verwertungsrechte im vermögensrechtlichen Sinne spielen eine nur untergeordnete Rolle. Das ist zunächst ein semantisches Problem. In den juristischen Texten und Gesetzen wird nur unzureichend (wenn überhaupt) berücksichtigt, dass der Begriff der Verwertung aus der Sicht des Wissenschaftlers ein ganz anderer ist als der aus der Sicht eines Verlegers. Die dem Verwertungsbegriff inhärente kommerzielle Bedeutung verführt dazu anzunehmen, dass auch der wissenschaftlichen Urheber so stark an dieser Verwertung interessiert ist, dass ihm eine auch monetäre Anerkennung (Vergütung) in jedem Fall zustehen muss. „Verwertung“ bedeutet in der Wissenschaft aber in erster Linie Veröffentlichung (vgl. 6.5):

197 Harald Müller, Stellvertretender Sprecher des Aktionsbündnis Urheberrecht für Bildung und Wissenschaft, hält diese Formulierung sogar für einen „Quantensprung im UrhWissG“ (mündliche und Email-Information). Das mag übertrieben sein, zumal dieser Sprung dann schon $1996 \mathrm{im}$ WCT der WIPO erfolgt wäre; aber das höher zu gewichtende Interesse der Öffentlichkeit für den Zugriff und die Nutzung von Information, insbesondere aus und für Bildung und Wissenschaft, gegenüber den Interessen der Urheber und denen der Rechteverwerter ist kaum zu bezweifeln. 
„Die primären Interessen des Wissenschaftlers als Autor” so formuliert es Benjamin Bajon, "liegen in erster Linie darin, mit seinen Werken eine möglichst weite Verbreitung und Wahrnehmung zu erlangen." 198

Jeder Wissenschaftler ist an einer möglichst freien, freizügigen Nutzung des von ihm publizierten Wissens interessiert. Je freier die Werke eingesehen und genutzt werden können, desto höher ist die Wahrscheinlichkeit, dass die eigenen Werke wahrgenommen und zitiert werden und die weitere Entwicklung des Wissenschaftsgebiets befördert wird. Je mehr die Werke genutzt werden, desto höher ist die Chance der Reputationssteigerung der Urheber dieser Werke. Aber Reputation ist nicht das einzige Argument gegen Vergütung: Jeder Urheber in der Wissenschaft kann nur Urheber werden, wenn er auch schon Nutzer war. Wie könnte er den Anspruch auf freie Nutzung des Wissens Anderer erheben, wenn er selbst auf Verknappung der Nutzung seiner Werke setzte? Grundsätzlich besteht eine Interessensymmetrie zwischen Urheber und Nutzer (vgl. 6.8.1). Beides - das Reputations- und das Symmetrieargument - steht für die subjektive Bereitschaft der meisten Urheber in der Wissenschaft, auf Vergütung zu verzichten oder ihr nur geringe Bedeutung zuzuschreiben - schon gar nicht ist Vergütung der Anreiz zur Produktion neuen Wissens (ausführlich dazu in Kap. 8).

Fazit. Verwertung ist in der Wissenschaft in erster Linie Veröffentlichung. Die freie Verfügbarkeit des von einem Wissenschaftler veröffentlichten Werks ist der Wissenschaft systemimmanent, aber auch ein moralischer Imperativ - wenn er denn nicht die Rolle eines Trittbrettfahrers einnehmen will. Das Belohnungssystem der Wissenschaft beruht nicht auf monetärer, sondern auf reputativer Anerkennung.

\subsection{Die fatale Wirkung des Drei-Stufen-Tests}

“Largely leave science at the mercy of the three-step test.” (Reichman/Okediji 2012, 1400)

Der Drei-Stufen-Test hat stark dazu beigetragen, dass sich das Urheberrecht kommodifizierend in Richtung eines Handelsrechts entwickelt hat. Ursache dafür ist, dass der Drei-Stufen-Test - in 6.1 als (negative) Schranken-Schranke bezeichnet - sowohl restriktiv und tendenziell zugunsten der kommerziellen Verwertung angelegt bzw. restriktiv zu Lasten der Schrankenregelungen für die Nutzung ausgelegt wird. Das wirkt sich vor allem für Bildung und Wissenschaft negativ aus. In 6.1 wurde schon

198 (Bajon 2010) Interessenausgleich im Wissenschaftsurheberrecht?, S. 110 - mit Verweis auf (Wandtke/Grassmann 2006) Einige Aspekte zur gesetzlichen Regelung zum elektronischen Kopienversand im Rahmen des „Zweiten Korbs“, S. 893. 
auf die Entstehung des Drei-Stufen-Tests anlässlich der RBÜ Revision Conference in Stockholm 1967 hingewiesen. Anlass war die Einführung des bis dahin nicht explizit bestimmten Vervielfältigungsrechts. Dafür musste festgelegt werden, in welchem Ausmaß Schrankenregelungen genehmigungsfreie Vervielfältigungen zulassen sollten. ${ }^{199}$ Tatsächlich bezog sich diese erste Version des Drei-Stufen-Tests zunächst nur auf Vervielfältigungshandlungen. Dieser Drei-Stufen-Test wurde dann mit der 1971 erfolgten Revision der Berner Konvention verbindlich. ${ }^{200}$ In der deutschen Fassung von 2004 lautet er:

Der Gesetzgebung der Verbandsländer bleibt vorbehalten, die Vervielfältigung in gewissen Sonderfällen unter der Voraussetzung zu gestatten, dass eine solche Vervielfältigung weder die normale Auswertung des Werkes beeinträchtigt noch die berechtigten Interessen des Urhebers unzumutbar verletzt. [kursiv von RK]

Aber erst mit dem TRIPS-Agreement von $1994^{201}$ wurde der Drei-Stufen-Test zu einem allgemein anzuwendenden Instrument. Seitdem werden Schrankenregelungen, einschließlich der direkt auf Wissenschaft bezogenen, immer an dem Kriterium des Drei-Stufen-Tests überprüft. Es ist zu einfach, die immer stärker werdende Dominanz der kommerziellen Verwertungsinteressen gegenüber den Nutzungsinteressen (hier vor allem in Bildung und Wissenschaft) an nur einem Punkt festzumachen. Aber die Entscheidung, in die völkerrechtlich verbindliche Berner Konvention und dann auch in die TRIPS Vereinbarung den Drei-Stufen-Test als einschränkende Bedingung für Schrankenregelungen in das Urheberrecht einzuführen, hatte doch starken Einfluss auf diese für Bildung und Wissenschaft negative Entwicklung. Durch die Verwendung von unbestimmten Rechtsbegriffen im Drei-Stufen-Test - "certain special cases" in Stufe 1; "normal exploitation" in Stufe 2; "legitimate interests of the author” in Stufe 3 - ist große Unsicherheit darüber entstanden, welche Handlungen zum Nutzen von Wissenschaft (und Bildung) als erlaubt anzusehen sind:

The decision to deal with the principal exception for science under the newly enacted three-step test of Article 9(2), rather than by means of a separate provision, introduced new levels of uncertaincy about the scope of permissible scientific activities without mandating any specific action favoring scientific research as such. ${ }^{202}$

199 Vgl. dazu den Artikel Drei-Stufen-Test (Urheberrecht) in der deutschsprachigen Wikipedia https://bit.ly/2kphJp1); zur wissenschaftlichen Auseinandersetzung um den Drei-Stufen-Test vgl. (Senftleben 2004) Copyright, limitations and the three-step test; (Senftleben 2010) The international three-step test.

200 Article 9(2) BC: “[...] to permit the reproduction of such works in certain special cases, provided that such reproduction does not conflict with a normal exploitation of the work and does not unreasonably prejudice the legitimate interests of the author."

201 TRIPS - https://bit.ly/2IBAm0u.

202 (Reichman/Okediji 2012) When copyright law and science collide, S. $1379 \mathrm{f}$. 
Der Drei-Stufen-Test wirkt dadurch besonders rigide, dass jeder Stufe für sich schon Genüge geleistet sein muss: "If one factor is not satisfied, the inquiry ends and the limitation or exception will be found in non-compliance with the threestep test." ${ }^{203}$ Das hat vor allem Konsequenzen mit Blick auf die zweite Stufe ("do not conflict with a normal exploitation of the work"), welche sehr oft von der Verlagswirtschaft als „Killer“-Kriterium verwendet wird. Allerdings wird diese restriktive Sicht, wie sie sich aus TRIPS entsprechend den Interessen der (handelsorientierten) WTO herleitet, heute nicht mehr so unbedingt in der Rechtswissenschaft geteilt. Exemplarisch dafür die von zahlreichen Urheberrechtswissenschaftlern verfasste „Declaration“ von 2010204. Diese Erklärung geht davon aus, dass das Urheberrecht in erster Linie dem „öffentlichen Interesse“ diene. Um dieses Ziel des Urheberrechts zu erreichen, schlagen die Autoren der Erklärung eine Interpretation des Drei-Stufen-Tests vor, durch die dessen restriktive Auslegung und Anwendung verhindert werden kann. Der Drei-Stufen-Test hat sich tatsächlich, so (Geiger 2006), zu einer Bedrohung für ein ausgewogenes Urheberrecht erwiesen. Auch für die „Erklärung“ sollte durch den Drei-StufenTest ,eine angemessene und ausgeglichene Anwendung von Ausnahmen und Beschränkungen“ erreicht werden. ${ }^{205}$ Gefordert wird insbesondere, dass nicht nur die Interessen der Rechtsinhaber durch den Test geschützt werden, sondern auch „Drittinteressen“ - das kann im Zusammenhang von Bildung und Wissenschaft als Interesse der Öffentlichkeit interpretiert werden. Die Erklärung spricht das auch direkt an: „Das öffentliche Interesse ist besonders offenkundig im Bereich von Werten, die durch Grundrechte untermauert werden. “ Gemeint sind hier Informations- und Wissenschaftsfreiheit. Auch der Drei-Stufen-Test kann, so die Erklärung, nicht kontextlos interpretiert und angewendet werden, sondern nur im Zusammenhang von menschen- und verfassungsrechtlichen Prinzipien (Menschenrechten und Grundfreiheiten). Für die Auslegung des Drei-Stufen-Tests durch Rechtsetzung und Rechtsprechung regt die Erklärung an, von folgenden Prinzipien auszugehen:

(1) „Der Drei-Stufen-Test stellt eine unteilbare Gesamtheit dar.“

(2) „Der Drei-Stufen-Test erfordert nicht, dass Ausnahmen und Beschränkungen eng auszulegen sind. Sie sind nach Sinn und Zweck auszulegen.“

(3) „Bei der Anwendung des Drei-Stufen-Tests sollen die Interessen der ursprünglichen Rechtsinhaber ebenso berücksichtigt werden wie jene der Rechtsinhaber.“

203 (Cox 2012) United States four fair use factors and the WTO Three-Step Test.

204 (Geiger et al. 2010) A balanced interpretation of the „Three-step test“. Vgl. (Geiger et al. 2013) The three-step-test revisited.

205 (Erklärung 2010) Deutsche Übersetzung von (Geiger et al. 2010) (FN 204) - https://bit.ly/ 2YoHTa5. 
(4) Insgesamt solle der Drei-Stufen-Test in einer Weise ausgelegt werden, dass „die berechtigten Interessen Dritter berücksichtigt werden, ... einschließlich öffentlicher Interessen, insbesondere an wissenschaftlichem Fortschritt und kultureller, sozialer und wirtschaftlicher Entwicklung.“

Die Praxis aber sieht anders aus. Die „Erklärung“ von 2010 ist sicher nicht einfach in der Schublade der vergessenen Initiativen verschwunden, aber wirklich beachtet wurde sie vor allem in der Politik nicht. Immer wieder reichte schon der Verweis auf die „normale“ Verwertung aus, um eine für Bildung und Wissenschaft offenere Schrankenregelung dann doch enger zu fassen bzw. enger auszulegen. Ein schon erwähntes Beispiel ist die Ausklammerung von Zeitungsartikeln aus den Schrankenregelungen des UrhWissG 2017/18. Der Gesetzgeber folgte dem Lobbyingdruck der Zeitungsverlage, die kostenpflichtige Bereitstellung von Archivbeständen als normale Verwertung (im Sinne der zweiten Stufe) zu behaupten. Für die Verlagswirtschaft war und ist es immer ein „Totschlagargument“ gegen jede offenere Schrankenregelung. Die Rechtsprechung, insbesondere von BGH, BVerfG und EuGH, hat immer wieder den Drei-Stufen-Test herangezogen. ${ }^{206}$ Vor allem durch die zweite Stufe wird die normale Verwertung von Wissens-/Informationsobjekten durch Verlage geschützt. Auch hier zeigt sich, dass die Verwendung von unbestimmten Rechtsbegriffen - hier von „normal“ - eine Auslegung möglich macht, die sich an dem aus der analogen Welt stammenden Prinzip der Auflagenhöhe bzw. der verkauften Exemplare orientiert. Zudem folgt aus der rigiden Interpretation der ersten Stufe des Drei-Stufen-Tests (Nutzung nur als Sonderfall erlaubt) durch die Gerichte, aber auch durch die Arbeiten der Fachwissenschaft, dass die freie Nutzung, hier in Bildung und Wissenschaft, nur als die Ausnahme von der kommerziellen, verknappenden Verwertung anzusehen ist. Diese Annahme, dass die kommerzielle Nutzung auch in Bildung und Wissenschaft der Normalfall ist, ist heute angesichts des Open-Access-Publizierens nicht mehr aufrechtzuhalten. Am Ende dieses Abschnitts wird ein Vorschlag für einen Drei-Stufen-Test gemacht, der quasi in einer Kopernikanische Wende diesen gänzlich umdreht. Im Folgenden wird nur an drei Beispielen belegt ${ }^{207}$, welche negative Folgen die restriktive Anwendung des Drei-Stufen-Test gehabt hat.

206 Vgl. (Reschke 2010) Die verfassungs- und dreistufentestkonforme Auslegung der Schranken des Urheberrechts.Insbesondere Kap. 3 und 4.

207 (Geiger 2006) The Three-step test, a thread to a balanced copyright law? und (Griffiths 2009) The 'Three-Step Test' in European Copyright Law. Dort viele weitere Beispiele für die negativen Folgen der restriktiven Auslegung des Drei-Stufen-Tests. 
a) In der EU Directive 96/9/EC von 1996 „On the legal protection of databases“ gibt es über Article 6, (2), b eine Ausnahmeregelung, die es nahelegt, dass die an sich exklusiv geschützten Datenbanken sehr freizügig für Zwecke von Bildung und Wissenschaft genutzt werden können: „where there is use for the sole purpose of illustration for teaching or scientific research“. Aber es folgt ein Abs. (3), der Abs. (2) durch Verweis auf den Drei-Stufen-Test zugunsten des legitimen Interesses der Rechtsinhaber relativiert: „In accordance with the Berne Convention for the protection of Literary and Artistic Works, this Article may not be interpreted in such a way as to allow its application to be used in a manner which unreasonably prejudices the rightholder's legitimate interests or conflicts with normal exploitation [kursiv - RK] of the database.“

b) Da Gerichte häufig dazu neigen, den Drei-Stufen-Test sehr eng auszulegen, scheut sich oft der jeweilige Gesetzgeber, so auch in Deutschland, weitergehende Schrankenregelungen zugunsten von Bildung und Wissenschaft in das Urheberrecht aufzunehmen. Ein Beispiel dafür ist die Umsetzung des Art. 5 (3), a aus der InfoSoc-Richtlinie von 2001, der eine sehr freizügige, allein am Zweck der Nutzung orientierte Nutzung zu erlauben scheint. Erlaubt seien Vervielfältigungen, die öffentliche Wiedergabe und die öffentliche Zugänglichmachung (entsprechenden den Art. 2 und 3 der Richtlinie)

für die Nutzung ausschließlich zur Veranschaulichung im Unterricht oder für Zwecke der wissenschaftlichen Forschung, sofern ... die Quelle, einschließlich des Namens des Urhebers, wann immer dies möglich ist, angegeben wird und soweit dies zur Verfolgung nicht kommerzieller Zwecke gerechtfertigt ist.

Auf den Wortlaut von Art. 5 (3), a kann man sich aber nicht direkt berufen. Art. 5 (5) der InfoSoc-Richtlinie macht es sehr deutlich, dass alle Schrankenregelungen, sich an dem Drei-Stufen-Test zu orientieren haben: “The exceptions and limitations provided for in paragraphs 1, 2, 3 and 4 shall only be applied in certain special cases which do not conflict with a normal exploitation of the work or other subject-matter and do not unreasonably prejudice the legitimate interests of the rightholder." Trotzdem hatte das deutsche Justizministerium 2002 in seinem Referentenentwurf für den neuen $\S 52 a$, der die EU-Vorgabe umsetzen sollte, ausreichenden Spielraum gesehen und die von der EU vorgesehenen Regelung in Art. 5 (3), a tatsächlich nicht weiter eingeschränkt, sondern sich allein an dem Zwecke der Nutzung in Bildung und Wissenschaft orientiert (vgl. den Text des BMJ in 10.1). Aber schließlich wurde aus einem freizügigen Referentenentwurf durch Empfehlung des Rechtsausschusses und mit Bundestagsbeschluss ein §52a mit vielen Einschränkungen wie „kleine Teile eines Werkes“, „Werke geringen Umfangs“ und auch nur soweit dies durch den jeweiligen „Zweck geboten und zur Verfolgung nicht kommerzieller Zwecke gerechtfertigt ist“. Das ist der „Erfolg“ des Drei-Stufen-Tests. 
c) Das dritte Beispiel für die Folgen und die Interpretation des Drei-Stufen-Tests zeigt, dass auch eine sowieso schon eng angelegte Schrankenregelung wie $§ 52 a$ nicht davor schützt, dass Verlage nicht zögern, mit Berufung auf den Drei-Stufen-Test gegen die Nutzungspraxis in Bildung und Wissenschaft zu klagen. Dieses Beispiel ist aber auch deshalb interessant, weil möglicherweise die Rechtsprechung beginnt, vor allem durch die oberen Instanzen wie BGH, sich mit der bloßen Berufung auf den Drei-Stufen-Test nicht mehr zufrieden zu geben. Die Semantik der drei Stufen ist wegen der Verwendung von unbestimmten Rechtsbegriffen offen. Die Auslegung des BGH beim Urteil zu §52a deutet an, dass sich so etwas wie eine Leitidee gegen die Dominanz des kommerziellen Verwertungsanspruchs andeutet. Das war vermutlich nicht die Intention des BGH. Aber dessen Argumente, zu Ende gedacht, könnten zu einer Reformulierung des Drei-Stufen-Tests führen, die am Ende dieses Abschnitts vorgeschlagen wird. Worum ging es?

Bei der Klage gegen die Fernuniversität Hagen hatte sich der Verlag auf die Regelung in §52a bezogen (dazu vgl. 10.1), dass jede Nutzung von Lehrbüchern für Schulen „stets nur mit Einwilligung des Berechtigten zulässig“ erfolgen dürfe. Diese Vorschrift wurde auch auf das strittige Buch „Meilensteine der Psychologie“ übertragen, da es sich dabei auch um ein Lehrbuch handele. Weiter hatte der Verlag damit argumentiert, dass diese unzulässige Nutzung

dem Drei-Stufen-Test des Art. 5 Abs. 5 der Richtlinie 2001/29/EG zur Harmonisierung bestimmter Aspekte des Urheberrechts und der verwandten Schutzrechte in der Informationsgesellschaft nicht stand[halte]. Das Erfordernis der Beschränkung des Zugänglichmachens auf bestimmte Sonderfälle sei nicht erfüllt; da es um den Sonderfall in der Ausnahme gehe, könne dieser nicht in der Veranschaulichung im Unterricht oder der Zugänglichmachung liegen. Das Zugänglichmachen beeinträchtige die normale Verwertung des Werkes; da nur die auf der Lernplattform eingestellten Beiträge Pflichtlektüre und Prüfungsgegenstand seien, sei ein Erwerb des Buches für die Studierenden nicht mehr erforderlich. Unter diesen Umständen würden auch die berechtigten Interessen der Rechtsinhaber ungebührlich verletzt. ${ }^{208}$

Der BGH hat darauf doppelt reagiert. Beides ist für die auch hier geführte Diskussion um Reichweite oder sogar Sinn des Drei-Stufen-Tests einschlägig und allgemein um die Auslegungsoffenheit, kreative Hermeneutik, für die Gerichte. Zum einen wies der BGH den Vorwurf zurück, den sich noch das Berufungsgerichts des OLG zu eigen gemacht hatte, dass es sich bei der Veranschaulichung im Unterricht nicht um den in der ersten Stufe des Tests vorgesehenen Sonderfall handele. Seitdem weiß man genauer, was ein „Sonderfall“, vor allem mit Blick auf Bildung und Wissenschaft bedeutet.

208 Zitat aus der Begründung des BGH-Urteils. 


\begin{abstract}
„Dem“, so der BGH, „kann nicht zugestimmt werden. Die hier in Rede stehende Bestimmung des §52a Abs. 1 Nr. 1 UrhG regelt einen bestimmten Sonderfall und ist daher auch immer nur in diesem bestimmten Sonderfall anwendbar. Sie beschränkt das Recht des Urhebers zum Öffentlich-Zugänglichmachen seines Werkes für den besonderen Fall, dass veröffentlichte kleine Teile dieses Werkes zur Veranschaulichung im Unterricht an Hochschulen ausschließlich für den bestimmt abgegrenzten Teil von Unterrichtsteilnehmern öffentlich zugänglich gemacht werden, soweit dies zu diesem Zweck geboten und zur Verfolgung nicht kommerzieller Zwecke gerechtfertigt ist. Anders als das Berufungsgericht wohl gemeint hat, verlangt die erste Stufe des Drei-Stufen-Tests nicht, dass die einen Sonderfall regelnde Ausnahme oder Beschränkung ihrerseits nur in einem - bezogen auf die Schrankenregelung Sonderfall angewendet wird.“
\end{abstract}

Weiter stimmte der BGH der Ansicht des OLG nicht zu, dass „das Öffentlich-Zugänglichmachen der in Rede stehenden Beiträge [...] die normale Verwertung des Werkes (zweite Stufe) [beeinträchtige]“. Abgesehen davon, dass die Übertragung der Regelung für die Nutzung von Schulbüchern auf Lehrbücher an Hochschulen ohnehin fragwürdig ist, stellt der BGH fest:

Das Werk „Meilensteine der Psychologie“ ist nicht allein für den Unterrichtsgebrauch an Hochschulen bestimmt; es richtet sich in gleicher Weise an psychologisch Interessierte, Studierende und Fachleute. Die normale Werkverwertung wird daher nicht dadurch beeinträchtigt, dass der Erwerb des gesamten Buches [...] für die Studierenden, die den Kurs „Einführung in die Psychologie und ihre Geschichte“ belegt haben, nicht mehr erforderlich sein mag, weil lediglich die auf der Lernplattform eingestellten Teile des Werkes Pflichtlektüre und Prüfungsgegenstand sind.

Der BGH stellt damit die Weichen für eine semantische und vor allem pragmatische Auslegung des wohl wichtigsten bzw. wohl am meisten reklamierten Kriteriums des Drei-Stufen-Tests, nämlich der „normalen Verwertung“ in der zweiten Stufe. Der BGH konnte, anders als das OLG, nicht erkennen, dass die Bedingung der dritten Stufe des Tests, die ungebührliche Verletzung der Rechte des Rechtsinhabers, erfüllt sei. Vor allem hätten Kläger und OLG nicht die für die dritte Stufe erforderliche Interessenabwägung durchgeführt. Es konnte also von Kläger und OLG nicht belegt werden, ,ob das Bedürfnis an einem Zugänglichmachen die Beeinträchtigung des Rechtsinhabers überwiegt“ oder eben nicht. Eine bloße Berufung auf die dritte Stufe reicht nicht aus. Es muss von Fall zu Fall durch eine Interessenabwägung entschieden werden. Mit diesem Vorschlag näherte sich der BGH dem Prüfverfahren für das Fair use im US-amerikanischen Copyright an (vgl. 12.4).

Durch das Urteil dürfte jetzt für folgende Rechtsprechungen klar sein, dass durch genehmigungsfreie Schrankenregelungen nicht per se eine Verletzung von Interessen der Rechtsinhaber (vor allem der Urheber selbst) angenommen werden kann. Es müssen in jedem Fall sorgfältig die allgemeinen Interessen (wohl der Rechtsinhaber und der Öffentlichkeit) an einer Zugänglichmachung und an der 
Nutzung (in dem von der jeweiligen Schranke erlaubten Umfang) gegenüber den Interessen der Verwertung abgewogen werden. „Normal“ und „Verwertung“ muss jeweils semantisch und pragmatisch überprüft werden. Vor allem mit Blick auf die dritte Stufe des Tests (Wahren der Interessen der primären Rechtsinhaber) darf man für Bildung und Wissenschaft davon ausgehen, dass jeder Autor ein höheres Interesse am Zugang und der Wahrnehmung von anderen Personen zu/an seinen Werken hat als ein Interesse, den Zugang durch rigide Inanspruchnahme seiner durch das Urheberrecht geschützten Rechte einzuschränken oder sogar auszuschließen. Insgesamt wird im Urteil deutlich, dass die bei so gut wie jeder Schrankenregelung vor allem von der Interessenvertretung der Verlage (sprich: Börsenverein) stereotyp vorgebrachte Kritik, sie führe zur Enteignung und sei ein Verstoß gegen den Drei-Stufen-Test, keine Grundlage hat. Auch der Stellenwert von geistigem Eigentum und der von Schranken-Schranken wie der Drei-StufenTest ist nicht wie in Stein gemeißelt. Deren Verständnis entwickelt sich mit neu zur Geltung gebrachten Werten und Leitideen, bis sie sich zu einer Ausprägung des aktuellen Zeitgeistes verdichten. Umso besser, wenn dies zuweilen mit juristischer Argumentation, wie am Beispiel des BGH-Urteils gezeigt, im Ergebnis übereinstimmt.

In der Gesetzgebungspraxis ist das aber noch so gut wie gar nicht angekommen. Der Drei-Stufen-Test wird nicht hinterfragt. Kaum wird problematisiert, was der „Sonderfall“ ist, auch nicht was „normale Verwertung“ sein soll und auch nicht welches die „berechtigten Interessen der Urheber“ sind. Allein schon die Sorge, dass eine urheberrechtliche Regelung mit dem Drei-Stufen-Test nicht verträglich sein könnte, reichte bis heute (bis in das UrhWissG von 2017/18) aus, um Vorschläge für ein wissenschaftsfreundliches Urheberrecht abzuwehren. Es spricht einiges für die Annahme, dass aus Respekt oder aus Furcht vor der Auslegung des Drei-Stufen-Tests das Konzept einer ABWS 2017 aufgegeben wurde. Der deutsche Gesetzgeber hat immer wieder darauf hingewiesen, dass für weitergehende Lösungen im Wissenschaftsurheberrecht die unionsrechtlichen Voraussetzungen fehlen. Im Hintergrund war der Politik aber sicher auch bewusst, dass die WTO auf die Einhaltung von Vereinbarungen wie TRIPS achtet, so dass strenge Strafen drohen, wenn die Grenzen des Drei-Stufen-Tests nicht eingehalten werden. ${ }^{209}$

Das führt uns am Ende zu dem Versuch, den Drei-Stufen-Test zeitgemäß „umzudrehen“. Die bisherige Auslegung des Tests zielte darauf ab, dass Ausnahmen von der exklusiven Verwertung von Werken, die durch Regelungen zum geistigen Eigentum geschützt sind (Urheberrecht, Copyright), a) nur in bestimmten besonde-

209 Vgl. (Hugenholtz/Okediji 2007) Conceiving an international instrument on Limitations and exceptions to copyright. 
ren Fällen erlaubt sein sollen, wenn sie b) nicht im Widerspruch zu einer normalen Verwertung stehen und dadurch c) keine unzumutbaren Nachteile für den Urheber entstehen. Hier einige Argumente, warum der Test quasi umgedreht werden sollte:

a) Seit einigen Jahren zeichnet sich ab, dass, mit Blick auf Bildung und vor allem auf Wissenschaft, das überwiegende Geschäftsmodell in elektronischen Räumen sich in Richtung einer freien offenen Nutzung (nach dem Open Access-Prinzip) entwickelt. Nicht die freie Nutzung wird im Sinne der ersten Stufe die Ausnahme sein, sondern die proprietäre kommerzielle Verwertung. Diese Priorität in Richtung Open Access wird heute auch schon durchgängig auf den verschiedenen politischen Ebenen favorisiert (ausführlicher in Kap. 14). Der freie und offene Umgang mit Wissen und Information findet immer mehr Akzeptanz in der Öffentlichkeit, und er war auch das (erreichte) Ziel von den DEAL-Verhandlungen zwischen Verlagen und Vertretungen der Allianzorganisationen (vgl. 14.8). Er ist also kein Sonderfall, sondern wird eher zur Regel. Das muss allerdings die kommerzielle Verwertung nicht ausschließen. Im Sinne der zweiten Stufe ist dies aber nicht als normale Verwertung anzusehen.

b) Mit Blick auf die dritte Stufe des Drei-Stufen-Tests müsste die besondere Situation in Bildung und Wissenschaft stärker in Rechnung gestellt werden. Wie schon mehrfach betont, hat die Interpretation von „Verwertung“ als „,kommerzielle Verwertung“ für die Akteure in Bildung und Wissenschaft keinen Vorrang. Das monetäre Verwertungsinteresse ist in Bildung und Wissenschaft für Wissenschaftler kein primäres Motiv für Produktivität - schon gar nicht ist es entscheidend für Kreativität. Ohnehin wird in den meisten Fällen, vor allem durch Zeitschriftenpublikationen kein Einkommen erzielt. Vergütung und Vergütungsansprüche sind für die meisten (öffentlich finanzierten) Wissenschaftler eher eine juristische Fiktion, ein weiteres Als-ob-Verhalten, denn Realität. Es ist also keineswegs gegen das Interesse der Wissenschaftler, wenn über den Drei-Stufen-Test nicht mehr die Vergütung als Kompensation für den nun freien Zugang zu ihrem publizierten Wissen angesehen würde. In (Kuhlen/Brüning 2004) wurde schon 2004 ein positiver Drei-Stufen-Test auf Grund der sich entwickelnden Leitidee des freien offenen Umgangs mit Wissen und Information vorgeschlagen. ${ }^{210}$ Dabei war als dritte Stufe, die also den primären Interessen der Rechtsinhaber entsprechen soll, vorgesehen, dass „das Ausmaß der öffentlichen Verfügbarkeit in der Zuständigkeit und informationellen Autonomie der Urheber der jeweiligen Werke“ liegen soll.

c) Die Orientierung an dem individuellen Autoreninteresse, zudem überhöht durch den Autonomieanspruch, war damals der für selbstverständlich gehaltenen Einschätzung geschuldet, dass nur der Autor selbst über alles, was mit Veröf-

210 (Kuhlen/Brüning 2004) Chancen für einen innovativen Drei-Stufen-Test? S. 8. 
fentlichung zusammenhängt, entscheiden dürfe. Diese Einschätzung entspricht auch, zumindest in Deutschland, noch der herrschenden Meinung, nämlich, in Anwendung auf das Zweitverwertungsrecht (vgl. 11.3), dass eine Mandatierung zugunsten einer Open-Access-Publikation (gold oder grün) nicht mit Wissenschaftsfreiheit vereinbar sei (vgl. 11.3.6). Hier wird, 15 Jahre später, eine andere Position vertreten, die dem öffentlichen Interesse an freier Verfügung des publizierten Wissens entspricht. Wie es in vielen Ländern selbstverständlich geworden ist und wie es sich auch in vielen entsprechenden politischen Verlautbarungen, vor allem auch auf EU-Ebene, widerspiegelt, wird hier dafür plädiert, dem institutionellen Interesse ebenfalls Rechnung zu tragen.

d) Ergänzend wird die Position vertreten, dass die bis heute übliche Lizenzierungspraxis ebenfalls vom Kopf auf die Füße gestellt werden sollte. Nicht mehr soll die Öffentlichkeit für die Nutzung der Veröffentlichungen der Verlagswirtschaft in Bildung und Wissenschaft kostenpflichtige Lizenzen erwerben müssen, sondern die Verlage sollen (kostenpflichtige) Lizenzen für Nutzungsrechte an den (i.d. R. mit öffentlichen Mitteln unterstützt produzierten) Werken der Urheber/Autoren erwerben müssen - zu entrichten an die Institutionen der persönlichen Urheber. Das sollte auch das Ziel für zukünftige DEAL-Verhandlungen sein. Das schließt nicht aus, dass die Verlage bzw. allgemein die Content Provider für die von ihnen erstellte Dienstleistungen mit entsprechenden informationellen Mehrwerten Einnahmen erzielen können.

Fazit. Es ist tatsächlich bislang so, wie es (Reichman/Okediji 2012, 1400) formulieren, dass jede Schrankenregelung zugunsten von Bildung und Wissenschaft "largely leave science at the mercy of the three-step test”. Das gilt auch für das 2017/18 beschlossene UrhWissG in Deutschland und für die schließlich 2019 verabschiedete neue EU-Urheberrechts-Richtlinie, durch die das europäische Urheberrecht kaum wissenschaftsfreundlicher geworden ist. Die Restriktionen des Drei-Stufen-Tests sind weiter für das Unionsrechts verbindlich. Das muss nicht sein. Kreative, liberalere Auslegung des Drei-Stufen-Tests ist möglich (vgl. FN 204) und geschieht in Teilen der Rechtswissenschaft und zuweilen auch durch die oberen Gerichte. Ein mit Blick auf Bildung und Wissenschaft längst fälliger ganz neuer, dann positiver Drei-Stufen-Test wäre möglich und entspricht dem Stand der entwickelten Leitideen für den freien Umgang mit Wissen und Information. Ein Drei-Stufen-Test, der von der freien Nutzung als Regel ausgeht, sähe vor, dass eine kommerzielle Verwertung von in Bildung und Wissenschaft erstellten Werken a) nur in besonderen Fällen erlaubt ist, wenn b) gesichert ist, dass auf die Urheberschaft der originalen Werke referenziert wird und diese im öffentlichen Bereich frei für jedermann zugänglich sind, und wenn c) von den kommerziellen Verwertern Nutzungslizenzen von den primären Rechtsinhabern und ihren Institutionen erworben worden sind. 


\subsection{Fazit zu Kapitel 6}

Die zu Beginn des Kapitels schon zitierte (konditionierte) Einschätzung von Dreier/ Hilty

Sollte sich erweisen, dass die traditionelle Bauweise [des UrhG von 1965 - RK] nicht mehr für ein neues Haus taugt, das den aktuellen Herausforderungen den notwendigen Raum verschafft, sind neue Ideen gefordert, möglicherweise über das Gelände hinaus, auf dem das urheberrechtliche Haus heute steht

haben wir uns hier zu eigen gemacht. Einen alle Juristen überzeugenden Nachweis für die Untauglichkeit der „traditionellen Bauweise“ des Urheberrechtes werden wir in den vorangegangenen Abschnitten kaum erbracht haben. Aber die hier vorgebrachte Kritik an den Fundamenten des Urheberrechts - angefangen von der Fiktion des individuellen Schöpfers bis hin zu dem das bisherige Fundament sichernden Drei-Stufen-Test - deutet darauf hin, dass für ein zeitgemäßes Urheberrecht ein neues „Gelände“ und „neue Ideen“ erforderlich sind. Auf diesem Gelände und mit neuen auf gegenwärtigen Leitideen beruhenden Werten wie Nutzungsfreiheit kann dann sogar ein Recht für Bildung und Wissenschaft aufgebaut werden, das auf das den Titel „Urheberrecht“ mit dem individuellen Schöpfer im Mittelpunkt verzichtet und das die Nutzungsrechte zur Grundlage dieses Rechts macht. Nutzungsrechte beziehen sich umfassend auf die Rechte der Autoren, ihre Werke (im Sinne der Persönlichkeitsrechte im jetzigen Urheberrecht) zu nutzen, aber auch auf die Rechte der Nutzer und der Öffentlichkeit, die publizierten Werke (Informationsobjekte) frei verwenden und weiterentwickeln zu dürfen, aber auch auf die zu erwerbenden Erlaubnisse der Organisationen der Informationswirtschaft, aus den Werken Informationsprodukte und -dienstleistungen auf den Informationsmärkten anzubieten.

In den folgenden beiden Kapiteln werden „Eigentum/geistiges Eigentum“ und „Vergütung“ als im jetzigen Urheberrecht besonders starke Fundamente diskutiert mit dem vorweggenommenen Ergebnis, dass die über die beiden Fundamente abgeleiteten umfassenden Rechte nicht den „notwendigen Raum“ für ein „,neues Haus" schaffen, das Bildung und Wissenschaft brauchen, um umfassend und frei publiziertes Wissen zu nutzen. 
